\title{
Empirically downscaled temperature scenarios for northern Europe based on a multi-model ensemble
}

\author{
R. E. Benestad* \\ The Norwegian Meteorological Institute, PO Box 43, 0313 Oslo, Norway
}

\begin{abstract}
A number of empirically downscaled climate scenarios are presented for 115 locations in northern Europe, based on 17 different global climate scenarios, different choices of regions from which the predictor fields are taken, and employing a technique based on common principal components. A total of 48 different scenarios are estimated for each location, and the ensemble of this is used as a first-order measure of the 'most likely' extrapolation of the current climatic trends. The ensemble spread provides a crude measure of the uncertainties associated with these scenarios. The scenario spread is also used to explore the sensitivity of the results to the choice of analysis details and to identify common traits. The relatively good agreement amongst the various climate models suggests that they point to a common pattern for the winter and that the results may be regarded as robust. The common principal component approach implicitly involves quality control of these climate model scenarios, and the results suggest that most models produce realistic spatial temperature patterns, regardless of model resolution and sophistication.
\end{abstract}

KEY WORDS: Empirical downscaling $\cdot$ Common EOFs $\cdot$ Multi-model climate scenarios $\cdot$ Sensitivity study Resale or republication not permitted without written consent of the publisher

\section{INTRODUCTION}

Since Arrhenius (1896) proposed that atmospheric $\mathrm{CO}_{2}$ may have a warming effect on the Earth's surface, we have observed a gradual accumulation of the $\mathrm{CO}_{2}$ concentration in the atmosphere (IPCC 2001) as well as other so-called 'greenhouse gases'. Most of this longterm increase in the atmospheric greenhouse gas concentrations is believed to be a bi-product of increasing anthropogenic energy consumption. This build-up leads to a perturbation in the energy balance between the incoming solar radiation and the infrared radiation emitted from the Earth's atmosphere, and there are concerns about the effects of such an energy imbalance on our climate. Estimations of globally averaged temperature indicate warming over the past century (IPCC 2001). Although the global aspect of climate change is important for monitoring purposes and the

*E-mail: rasmus.benestad@dnmi.no understanding of our climate, it is the local climate shifts that will have direct effects on our future. Therefore, it is important to consider what implications global warming may have for regional climates.

The most recent global coupled atmosphere-ocean general circulation models (AOGCMs) tend to give a realistic description of the large-scale climatic features, such as the mean circulation patterns (i.e. the Hadley Cell and westerlies in the mid-latitudes), the coupled ocean-atmosphere processes in the tropics associated with the El Niño/Southern Oscillation (ENSO) (Collins 2000), and the shifts in the air masses often referred to as the North Atlantic Oscillation (NAO). But, the model topography has until now been crude, and features such as the Norwegian mountain ranges have not been represented realistically in these models (see Fig. 1). It is then no surprise that even the most recent AOGCM cannot give a good detailed description of regional climatic features. Analytical results from Grotch \& MacCracken (1991) may suggest 

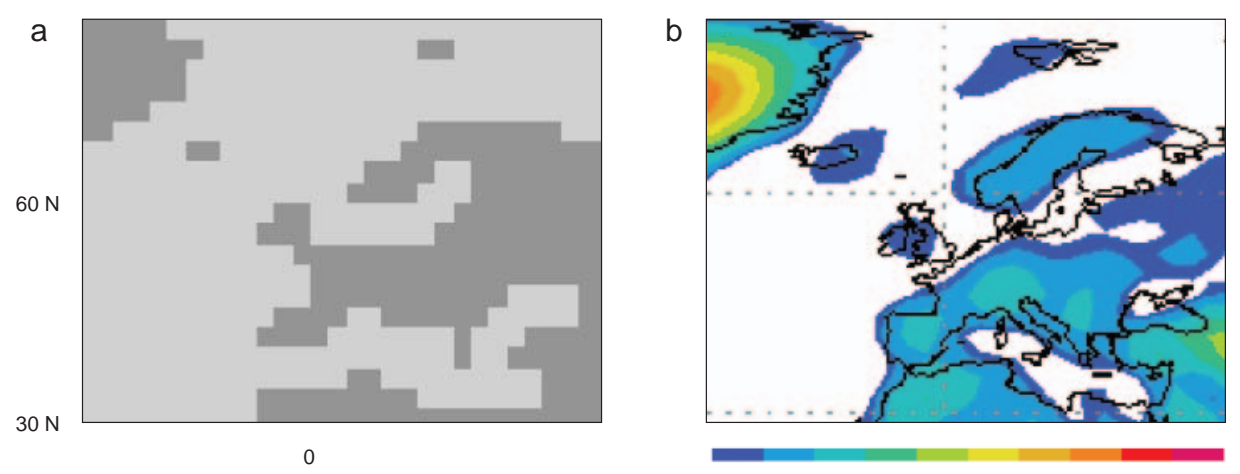

Fig. 1. (a) Land-sea mask for the Nordic countries used in the ECHAM4 model and (b) the ECHAM4 model topography (figures obtained from the IPCC Web site: http://ipcc-ddc.cru.uea.ac.uk)

that the global climate models cannot give a good description of features smaller than sub-continental scales.

Despite the caveats about the grid-scale representation of climate, it may still be possible to use the AOGCMs to describe local climate characteristics if the local climate is affected by large-scale features. Moreover, there may be information in large-scale climate anomalies that can be used to infer local climate variability. However, this requires extra knowledge about how the large-scale climatic features relate to the local climate variables. So-called downscaling models, based on either physical considerations (nested dynamical models used in dynamical downscaling; Christensen et al. 1998, Bjørge et al. 2000) or empirical studies (empirical or statistical downscaling) can be used to relate the large-scale climatic patterns to local scales. Here, we will focus on the empirical downscaling approach. Empirical models are based on statistical relationships between the local climate variations and large-scale climate anomalies (Zorita \& von Storch 1997, Kidson \& Thomson 1998, Heyen et al. 1996, Wilby et al. 1998, Crane \& Hewitson 1998).

Empirical downscaling has often used principal component analysis (PCA) to reduce the degrees of freedom. The PCA products are ideal for regression-type analysis because the set of PCA time series are mutually orthogonal. Barnett \& Preisendorfer (1987) used a combination of PCA and canonical correlation analysis (CCA) to develop empirical models for seasonal forecasting. Since the early 1990s, CCA has become a popular method for deriving relationships between large and small spatial scales (Karl et al. 1990, Zorita et al. 1992, von Storch et al. 1993, Noguer 1994) and has become an alternative to ordinary multivariate or multiple regression.

Downscaling analysis can provide more than just the local scenarios. Depending on the downscaling strategy, it is possible to incorporate a type of quality con- trol by searching for the same spatial structures in the model simulations as those identified in the actual climate to have an association with local climate anomalies. Thus, by comparing the similarities of the spatial patterns, their spectral properties, and the variance accounted for by these, it is possible to make some assessment of the quality of the model results.

A useful way of looking at the downscaling analysis is to regard the exercise as adding further information (from the actual world) to the model results, and this information is given by the statistical relationships based on historical observations and measurements. It is important to note that the empirical models assume that the historical relations between large-scale and local climate anomalies will also be true for the future. This 'assumption of invariability' implies that there is some degree of uncertainty attached to the empirically downscaled scenarios due to the possibility of future changes in the relationship between large and small scales. This assumption can be tested to some degree through a 2-step process: (1) calibrating a downscaling model on a subsection of the observations and using the remaining part of the record for validation, and (2) training the downscaling model on a subsection ('1860-1991') of the AOGCM results and a corresponding grid point value, then using the period '1990-2049' for validation. Evaluations carried out on the ECHAM4-GSDIO scenario by Benestad (2001b) suggest that the relationship between the large-scale anomalies and local climate variations is only slightly non-stationary and that empirical downscaling will give realistic results.

There are error sources other than the invariability assumption which increase the uncertainty associated with the prediction of future climates. The sources of uncertainties may be classified as (1) uncertainties about future emission scenarios, (2) climate model shortcomings, (3) internal variability, and (4) additional errors introduced by the downscaling analysis. The 
'greenhouse gas emissions' category (Source 1) is based on economics considerations and scenarios, which are outside the scope of this study.

Climate model shortcomings (Source 2) may imply systematic biases, for instance, due to a crude description of unresolved processes using statistical parameterisation schemes (also commonly referred to as 'model physics'). The imperfect description of clouds in the climate models is one of the most important sources of uncertainties (IPCC 2001). Another example of such model shortcomings is the artificial climate drift, due to a mismatch in the fluxes between the atmosphere and oceans described by the atmospheric and oceanic models. Yet another example of possible climate model shortcomings involves the description of sea-ice (Meehl et al. 2000). Parkinson et al. (2001) conducted a series of experiments with a climate model and reported high sensitivity to variations in the sea-ice concentrations in the Arctic, and even errors in the satellite-derived sea-ice products can lead to significant differences in model climates. A $66 \%$ reduction in the sea-ice concentration was reported to give as much as a $30^{\circ} \mathrm{C}$ increase in polar regions. Thus, different seaice conditions associated with the different model climates may be one important source of uncertainty. Shindell et al. (2001) found important differences between climate models which include and exclude a detailed description of the stratosphere. Hence, the omission of stratospheric processes common among many climate models, used for enhanced greenhouse gas studies, may increase the uncertainties associated with climate model shortcomings. Finally, the invariability assumption also applies to all parameterisation schemes relying on a statistical description of sub-grid point scales, and non-stationarity in the relationships described by such schemes may in fact be a greater problem than for the linear downscaling schemes. Furthermore, any such non-stationarity may vary with the spatial resolution.

Internal variations (Source 3), or natural fluctuations, increase the uncertainties associated with estimating trends; but these can be taken as uncertainties in the slope estimates (Press et al. 1989, Eq. 14.2.9) and are usually available from standard data-analysis tools. The importance of the internal variability can also be explored using surrogate data, a technique often referred to as Monte Carlo simulation. Errors introduced by the downscaling analysis (Source 4) can be attributed to the weak or non-linear relationship between large-scale climate and local anomalies, but the analysis will also be susceptible to errors if the climate model contains systematic errors.

This paper will embrace all of the types of uncertainties mentioned above except uncertainties associated with the non-stationarity assumption and emission sce- narios. There will be different emphasis on each type of uncertainty. The multi-model ensemble samples part of the uncertainties associated with differences in the model resolution and formulations, and trend statistics will provide some idea about the importance of natural variations. The use of different empirical downscaling models explores some of the sensitivity in the relationship between large and small scales. The primary objective of this paper is to present a number of scenarios for some locations in northern Europe, based on a new strategy employing common empirical orthogonal functions (EOFs) described by Benestad (2001b). Another important point is to assess the uncertainties associated with these. These aims justify the strategy of making many downscaled estimates using various global climate scenarios and different options for the downscaling analysis. The spread in these estimates is then taken as a first-order measure of the overall uncertainty associated with these scenarios. Any classification of the different climate models into 'poor' and 'good' is left for future studies.

Although, the climate simulations bear a time stamp in the form of the forcing record, the translation between model dates and actual dates is not well defined due to the poorly known climatic state in 1860 and arbitrary spin-up processes. The differences in the 4 ensemble members of the HadCM2 integrations demonstrate the importance of the initial conditions for the subsequent integration and trend estimation (Benestad 2000a). This matter is partly related to the strong natural variability on decadal time scales in the high latitudes which affect the trend analysis. A distinction will therefore be made in this paper between the actual time and the model date by expressing the model dates in inverted commas. Thus, the year 1990 means the real date with which historical observations may be associated, whereas the model year '1990' denotes a year in the model simulations which is meant to describe a model climate analogous to the actual 1990 climate.

\section{DATA AND METHODS}

The first step of data analysis is to let the data 'speak for itself' before adding subjective information as to which model is more realistic than others. However, the methodology employed here will nevertheless be able to identify those models which are useless through the embedded quality control of employing common EOFs. The philosophy of using many different scenarios from models with different degrees of sophistication is to look for a climate-change signal representing a common trait amongst the models, regardless of model resolution and differences in the 
Table 1. The various AOGCM scenarios used for downscaling future climatic trends. n: number of integrations made with the model; $x$-res, $y$-res: meridional and longitudinal resolutions; FA: flux adjusted

\begin{tabular}{|llrrll|}
\hline $\mathrm{n}$ & \multicolumn{1}{c}{ Model } & $y$-res & $x$-res & FA & \multicolumn{1}{c|}{ Country (Reference) } \\
\hline 1 & CSIRO (GSA) & 32 & 64 & Yes & Australia (Gordon \& O'Farrell 1997) \\
3 & CCCma (GSA) & 48 & 96 & Yes & Canada (Flato et al. 2000) \\
1 & ECHAM4/OPYC3 (GSDIO) & 64 & 128 & Yes & Germany (Roeckner et al. 1992, Oberhuber 1993) \\
1 & ECHAM4/OPYC3 (GSA) & 64 & 128 & Yes & Germany (Oberhuber 1993, Roeckner et al. 1996) \\
2 & ECHAM3/LSG (GSA) & 64 & 128 & Yes & Germany \\
4 & HadCM2 (GSA) & 73 & 96 & Yes & UK (Cullen 1993) \\
1 & HadCM3 (GSA+ozone) & 73 & 96 & No & UK (Gordon et al. 2000) \\
1 & NCAR-DOE (GSA) & 40 & 48 & No & USA \\
1 & GFDL-19 (GSA) & 40 & 48 & Yes & USA (Delworth et al. 1999) \\
1 & CCSR/NIES (GSA) & 32 & 64 & Yes & Japan (Emori et al. 1999) \\
1 & NCAR-CSM (GSA) & 64 & 128 & No & USA (Meehl et al. 2000) \\
& & & & & \\
\hline
\end{tabular}

climate-model parameterisation schemes. The common signal will be referred to as 'model consensus'. Furthermore, by including 'poor' and 'good' models, it is possible to explore the sensitivity of the results to the choice of climate model as well as the details of the downscaling analysis.

Table 1 lists the 17 different AOGCM scenarios used to produce downscaled temperatures. Fifteen of these were obtained from the IPCC Web site weak or nonlinear, one from the NCAR CCSM (National Center for Atmospheric Research Community Climate System Model) Web site (http://ipcc-ddc.cru.uea.ac.uk), and one directly from the Max Planck Institute, Hamburg (O. Vignes pers. comm.). These 17 different scenarios were computed using 10 different climate models. Two similar experiments were made with the ECHAM4/ OPYC3, but the microphysical parameterisations in one experiment (GSDIO) have been modified to describe the indirect effects of aerosols on climate and tropospheric ozone effects. It has been acknowledged that the cloud microphysical processes related to aerosols are not well known (IPCC 2001), and in that respect, these differences can be interpreted as uncertainties in the model formulation.

Common EOFs (Flury 1988, Sengupta \& Boyle 1993, Barnett 1999) were computed by combining gridded analysis of observed $T(2 \mathrm{~m})$ (temperature at $2 \mathrm{~m}$ height above the ground) over the period 1873-1998, spatially interpolated onto the model grid, with AOGCM results over the entire integration length. The method is described in detail in Appendix 1 and by Benestad (2001b). The gridded $T(2 \mathrm{~m})$ observations were produced by merging University of East Anglia temperatures from Jones et al. (1998) with the National Centers for Environmental Prediction (NCEP) reanalysis (Kalnay et al. 1996) temperatures, using projections of normal modes derived from the NCEP reanalysis. This product has been evaluated by Benestad (2000b), who used the large-scale temperature anomalies to hind- cast local temperatures with an empirical downscaling model and found a good correspondence for an independent evaluation period. This study focuses on results derived using $T(2 \mathrm{~m})$ as predictors, but some of the analysis is also derived using $T(850 \mathrm{hPa})$ and 500 to $700 \mathrm{hPa}$ thickness fields. It is also possible to use sealevel pressure (SLP) or geopotential heights, but these have not been included in this study. Benestad (2000a) compared local scenarios derived from $T(2 \mathrm{~m})$, SLP, and geopotential heights. It was found that scenarios based on SLP do not describe the warming trend very well, as a significant part of the warming is unrelated to shifts in the circulation regimes. Downscaling conducted with NCEP 500 and $700 \mathrm{hPa}$ geopotential heights, on the other hand, captured much of the wintertime warming, but resulted in an underestimation of the summer trends. Hence, these were not as robust as scenarios based on $T(2 \mathrm{~m})$.

The model calibration involved a step-wise screening test, and the empirical downscaling models were developed by calibrating the observational part of the common principal components individually against the station records. This approach has been evaluated and discussed in detail by Benestad (2001b). One model was used to describe each of the 85 homogenized NACD (North Atlantic Climatological Dataset; Frich et al. 1996) station monthly mean temperature series. The NACD records were supplemented with 30 Norwegian station series from the Norwegian Meteorological Institute (DNMI: Det Norske Meteorologiske Institutt) in the kriging analysis. The step-wise screening test employed a cross-validation analysis (Wilks 1995) based on the Pearson correlation. The coefficients estimated from the cross-validation ranged from 0.58 for Bodø in April to 0.91 in January. The lowest scores were associated with large predictor domains $\left(90^{\circ} \mathrm{W}-40^{\circ} \mathrm{E}, 40-75^{\circ} \mathrm{N}\right)$, and the scores were improved dramatically by reducing the region used for the predictor, e.g. a predictor domain equal to $20^{\circ} \mathrm{W}-40^{\circ} \mathrm{E}$, 
$50-75^{\circ} \mathrm{N}$ gives $\mathrm{r}=0.80$ for Bodø in April. In other words, the CCA-based models are associated with high skill as long as suitable predictor regions are used.

\section{RESULTS}

A consensus based on 17 different global climate scenarios (Fig. 2a) indicates a projected global mean temperature change between ' $1990^{\prime}$ ' and '2050' $(\Delta \mathrm{T})$ within the range of 0.5 to $1.5^{\circ} \mathrm{C}$, whereas recent 'fingerprint' and scaling analysis by Allen et al. (2000) suggests $\Delta T \approx 1.5$ to $2^{\circ} \mathrm{C}$ since the 'pre-industrial times' (or $\Delta T \approx 1.0$ to $1.5^{\circ} \mathrm{C}$ between ' $1990^{\prime}$ and ' $2050^{\prime}$ '). The analysis shown in Fig. $2 \mathrm{~b}$ shows a plume plot of the AOGCM-simulated temperature over Norway. Decadal temperature variations are stronger in the regional climate evolution than in the global mean. Furthermore, there is larger scatter among the AOGCM results on a regional scale, in line with the findings of Grotch \& MacCracken (1991). The projected regional warming during '1990' to '2050' over Norway is $\Delta T \approx 0.7$ to $3^{\circ} \mathrm{C}\left(0.1\right.$ to $0.5^{\circ} \mathrm{C}$ decade $\left.{ }^{-1}\right)$.

In order to investigate how the spread and similarities among the various global climate scenarios vary geographically, a map (Fig. 3) was produced showing the projected ensemble mean temperature change (black contours) between '1961-1990' and '2010-2039' and the inter-model spread (grey contours). The selection of models used to make this scenario was limited to the available pre-calculated scenarios for model period

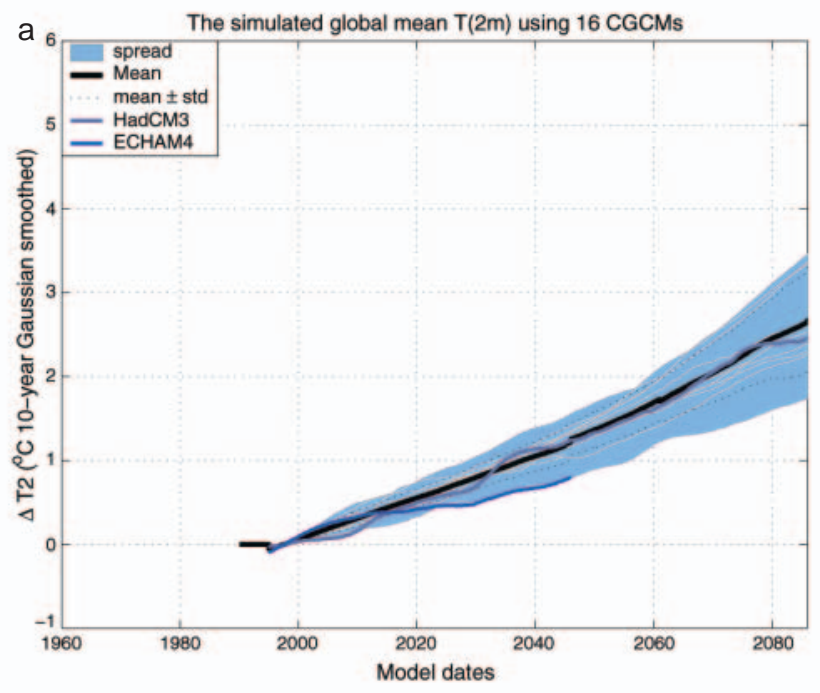

'2010-2039' from the IPCC data archive. The consensus based on these models suggests that the strongest warming occurs over the Arctic. One reason for this may be due to the insulating effect that ice has by separating the air from the sea and the presence of a positive ice-albedo feedback process (Hartmann 1994, Copley 2000, Meehl et al. 2000, Parkinson et al. 2001). When the sea-ice retreats, the air and sea become more strongly coupled. The near-surface air temperatures are strongly tied to the SSTs (not much colder than $0^{\circ} \mathrm{C}$ ), but sea-ice retreat also uncovers an underlying surface which often has much lower albedo than the ice, and thereby more of the solar irradiation is absorbed. The model consensus also suggests stronger warming over land than over maritime regions.

The largest differences in the model scenarios tend to be near Iceland and in the Arctic, where the warming is most pronounced. The standard deviation in $\Delta T$ for northern Europe is in the range of 0.5 to $1.5^{\circ} \mathrm{C}$, which is almost as large as the predicted change itself $\left(\Delta T=1\right.$ to $2^{\circ} \mathrm{C}$ from '1961-1990' and '2010-2039', which translates to 0.2 to $0.4^{\circ} \mathrm{C}$ decade $^{-1}$ ). However, Fig. 3 also reveals a few regions where the various climate model simulations indicate substantially different temperature trends, most notably over Iceland. The high spread in the estimates is due to 2 models with extreme values at single grid-points; those may be regarded as spurious results in a few scenarios not really representative of the degree of uncertainty (CSIRO GGA and GSA: annual warming greater than $7^{\circ} \mathrm{C}$ in the Denmark Strait between Iceland and Greenland by ' 2020 ').

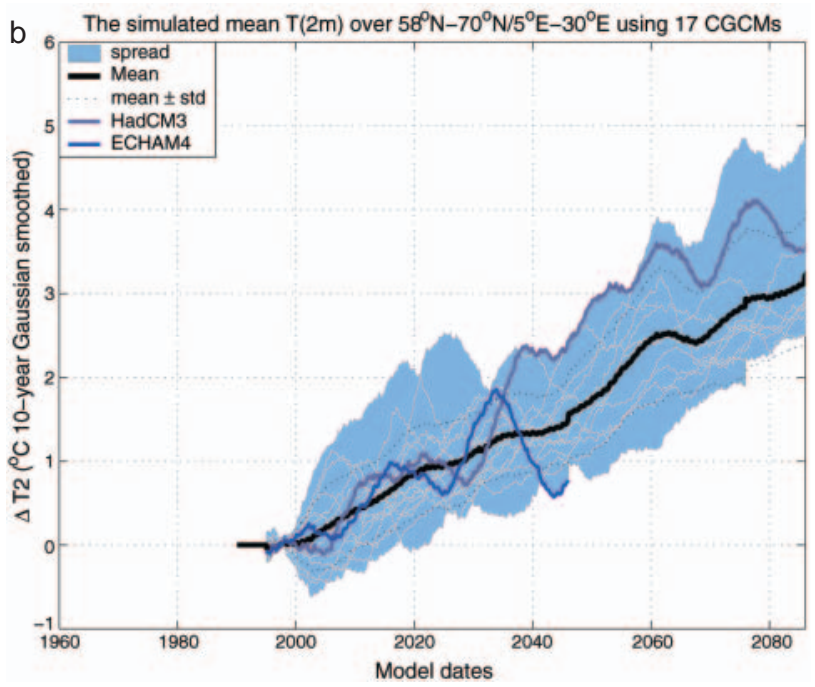

Fig. 2. (a) Estimates of the global mean $T(2 \mathrm{~m})$ (temperature at $2 \mathrm{~m}$ height above sea level) change based on 17 different AOGCM scenarios; (b) area mean temperature over $58-70^{\circ} \mathrm{N}, 5-30^{\circ} \mathrm{E}$. Thick curve: multi-model-ensemble mean; blue curve: ECHAM4 GSDIO estimates; grey curve: HadCM3 values; dotted curves: standard deviation away from the ensemble mean. The AOGCMs include HadCM3, ( $3 \times)$ CCCma, CSIRO, $(2 \times)$ ECHAM3/LSG, GFDL-R19, (4×) HadCM2, (2×) ECHAM4 (GSDIO and GSA), 
14 IPPC scenarios $\Delta \mathrm{T}_{\text {air }}(1961-1990$ to 2010-2039)

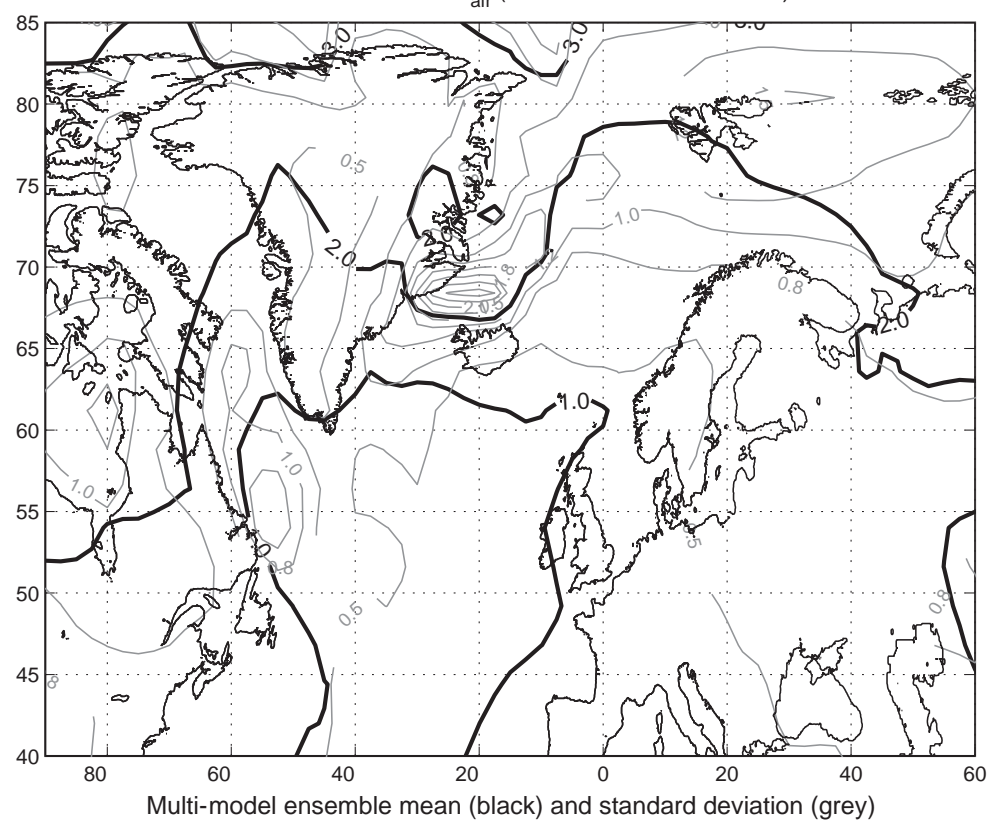

Fig. 3. The ensemble mean temperature change between '1961-1990' and '2010-2039', based on 14 IPCC models. The contours represent the ensemble spread (standard deviation). These temperature fields are the differences between '1961-1990' and '2010-2039' from (3×) CCCma, $(2 \times)$ CSIRO (GHG and GSA), ECHAM3/LSG, GFDL-R19, $(4 \times)$ HadCM2, CCSR/NIES, and NCAR-DOE, and they were obtained the IPCC data archive

Fig. 4 shows plume plots made from 47 differently downscaled January temperature projections at 8 different locations in northern Europe (locations shown in Fig. 5). The temperatures shown in these plume plots are anomalies with respect to the actual 1941-1990 climate. Table 2 gives the details about the AOGCM scenarios used as input values for the analysis, the predictor variables, and the regions from which the predictors were taken. The ensemble spread is represented by the shaded area in Fig. 4, whereas the thick solid curve gives the ensemble mean. It is evident from these plume diagrams that the various scenarios tend to describe similar long-term warming.

A good agreement among the downscaled results based on various AOGCM scenarios and downscaling options is evident in Fig. 6, and the population of the downscaled trend estimates is approximately normally distributed. Thus, the results seem to be robust, and the analysis points towards a common trait amongst the models, regardless of differences in the AOGCM resolution, parameterisation schemes and choices for the downscaling analysis: The spread in the January warming rate estimates is small for locations at lower latitude, such as Maastricht (Fig. 4a) and Copenhagen (Fig. 4c), but also for coastal places, such as Edinburgh (Fig. 4b) and Stykkisholmur (Fig. 4g). Natural variabil- ity can contaminate the trend analysis and will increase the range of estimates. Since the natural variations near the coasts are weaker than in continental-type climates, it is expected that this contamination is more severe for continental sites. But, the spread will of course also be affected by the differences in the AOGCM scenarios. The estimated warming trends range between -0.3 and $1.0^{\circ} \mathrm{C}$ decade ${ }^{-1}$, which is wider than the regional trends shown in Fig. 2b. The most notable difference between the downscaled and regional mean interpolated scenarios, however, is that the downscaling analysis tends to give higher warming-rate estimates. The tail into negative trends may be ascribed to sampling uncertainty using predictor domains that are too large (Benestad 2001b).

As a test of the sensitivity of the results to the choice of predictor domain, a downscaling analysis was carried out using a domain not covering the location of the predictand. Fig. 7 shows plume plots and distribution functions for stations located to the far north or west outside the predictor region. The scenarios for these locations have a larger scatter than for those locations further south. In the plume plot for Svalbard (Fig. 7b), downscaled January temperatures have strong departures from the mean trend, most notable a series of extreme cold events around '1875', '1930', '1945', and '2000'. Similar behaviour can be seen at Jan Mayen (Fig. 7c). It is possible that these cold events are associated with expansion of the sea-ice.

In contrast to the other scenarios, the estimates for Godthåb (Fig. 7d) on Greenland's southwest coast suggest long-term cooling. In comparison the AOGCM results suggest a general warming even for Greenland (Fig. 3). The reason for these differences can be seen in Fig. 5, showing the predictor domains, and Table 2, listing the calculation details, and is due to the fact that Godthåb lies outside all the predictor regions except for the natl domain used in only 4 of the 47 calculations. The empirical downscaling models apply CCA to the detrended time series and therefore tend to latch

Fig. 4. Time-series plumes showing the multi-model ensemble mean and spread. The plots show multi-model ensembles of empirical downscaled January temperature for (a) Maastricht (Belgium), (b) Edinburgh (UK), (c) Copenhagen (Denmark), (d) Oslo (Norway), (e) Stockholm (Sweden), (f) Helsinki (Finland), (g) Stykkisholmur (Iceland), and (h) Karasjok (Norway). Note the different scales on the $y$-axes 

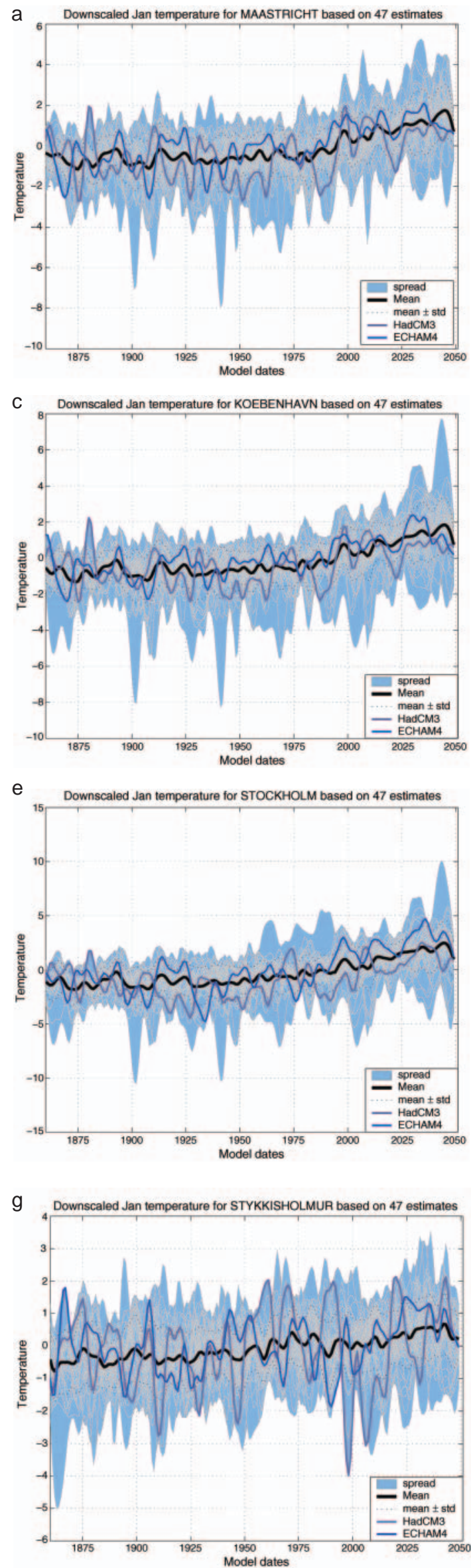
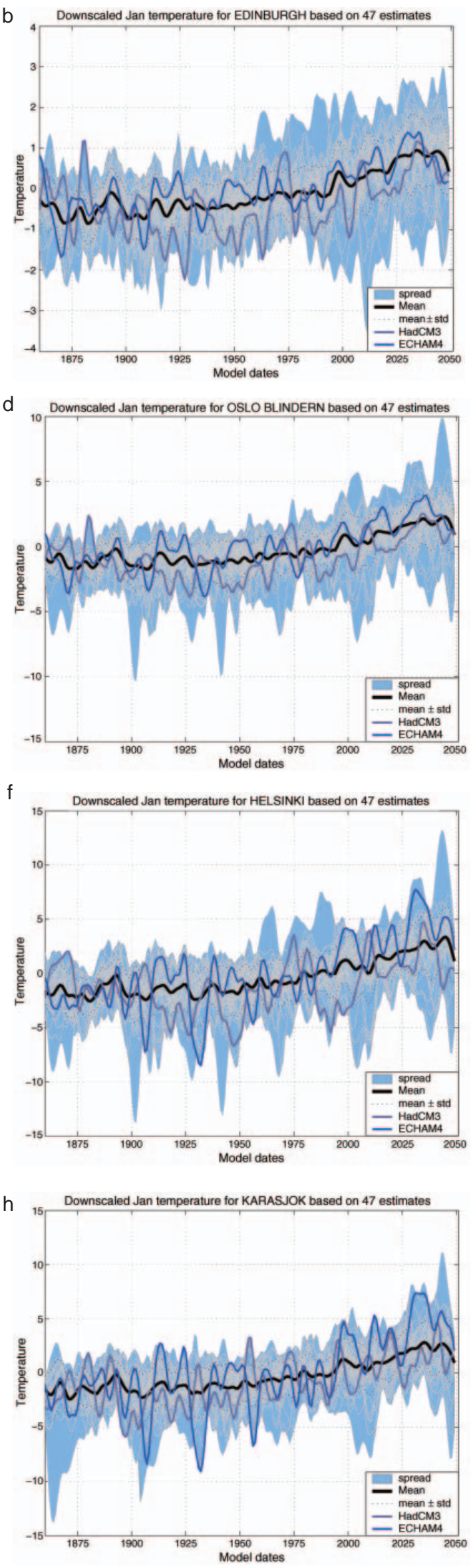


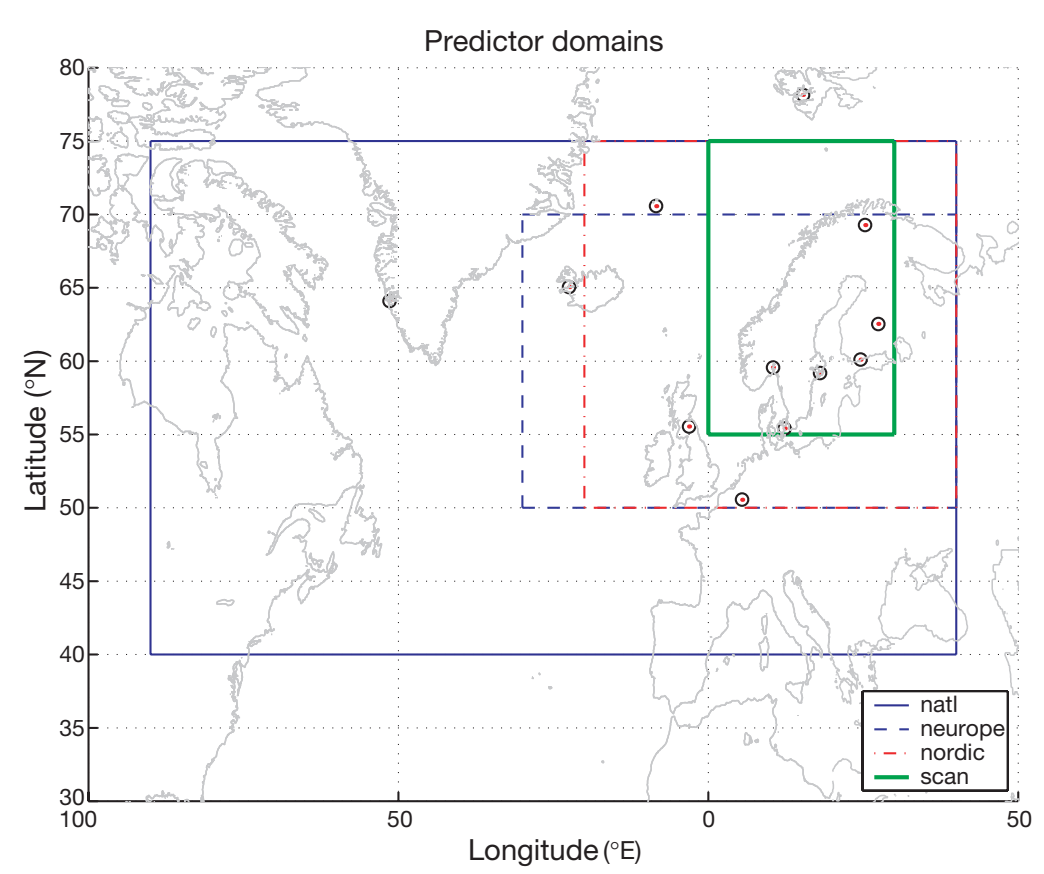

Fig. 5. Map showing the locations of the NACD (North Atlantic Climatological Dataset) stations shown in this paper and the predictor domains

with the same observations and future climatic trends are not known. Since the addition of model data to the observations in the common EOF analysis may influence the modal structures derived from the PCA, the observational part of the principal components may vary with different data combinations. Hence the various empirical models for the different climate models may achieve different cross-validation skills. The third and fourth columns in Table 3 list the Pearson cross-validation correlations for the January and July models respectively. For January, the highest scores $(\geq 0.91)$ are obtained with the ECHAM4-GSDIO, CCCma, and NCAR-CSM models when $T(2 \mathrm{~m})$ is used as predictor, whereas the ECHAM4-GSDIO 500 to $700 \mathrm{hPa}$ thickness yields the lowest score (0.71). For July, on the other hand, the ECHAM4GSDIO 500 to $700 \mathrm{hPa}$ thickness is associated with the best cross-validation results (0.80). The lowest July scores are found with the ECHAM4-GSDIO $T(850 \mathrm{hPa})$

on to the NAO signal, in which the temperature anomalies over Greenland have a different polarity to those over northern Europe. The Godthåb case serves as a warning with regard to how empirical downscaling analysis can be misleading and points to the importance of sensible choices for predictor domains.

When applying different downscaling models to a large number of climate models indiscriminately, there is a risk that unrealistic models will confound the end results. It is therefore important to carry out some form of model evaluation. It is difficult to validate the results because most of the empirical models are calibrated and NCAR-CSM T(2m) models. In other words, judging from the cross-validation based on the common EOFs, no climate model stands out as superior or inferior. The downscaling models demonstrate high skill in the description of local temperature variations.

Comparison between the variance accounted for by the leading common EOFs along the lines proposed by Sengupta \& Boyle (1993) can provide further insight into the realism of the climate models. This type of analysis is only a 'rule-of-thumb' method for deciding whether the spatial fields produced by the climate model are realistic or not, and does not provide infor-

Table 2. Details of the different downscaled estimates. $\mathrm{n}$ : number of estimates (total $=48$ ). Regions used for the predictors: natl, $90^{\circ} \mathrm{W}-40^{\circ} \mathrm{E}, 40-75^{\circ} \mathrm{N}$; neurope, $30^{\circ} \mathrm{W}-40^{\circ} \mathrm{E}, 50-70^{\circ} \mathrm{N}$; nordic, $20^{\circ} \mathrm{W}-40^{\circ} \mathrm{E}, 50-75^{\circ} \mathrm{N} ;$ scan, $0^{\circ} \mathrm{W}-30^{\circ} \mathrm{E}, 55-75^{\circ} \mathrm{N}(\mathrm{domains}$ are shown in Fig. 5)

\begin{tabular}{|c|c|c|c|c|c|c|c|}
\hline $\mathrm{n}$ & Model member & Run & Predictor & natl & neurope & nordic & scan \\
\hline 4 & ECHAM4/OPYC3 & GSDIO & $T(2 \mathrm{~m})$ & $\mathrm{v}$ & $\mathrm{v}$ & $\mathrm{v}$ & $\mathrm{v}$ \\
\hline 2 & ECHAM4/OPYC3 & GSA & $T(2 \mathrm{~m})$ & & & $\mathrm{v}$ & $\mathrm{v}$ \\
\hline 3 & ECHAM4/OPYC3 & GSDIO & $H(500-700 \mathrm{hPa})$ & & $\mathrm{v}$ & $\mathrm{v}$ & $\mathrm{v}$ \\
\hline 3 & ECHAM4/OPYC3 & GSDIO & $T(850 \mathrm{hPa})$ & $\mathrm{v}$ & $\mathrm{v}$ & & $\mathrm{v}$ \\
\hline 4 & NCAR-CSM & b006 & $T(2 \mathrm{~m})$ & $\mathrm{v}$ & $\mathrm{v}$ & $\mathrm{v}$ & $\mathrm{v}$ \\
\hline 6 & CCCma 1-3 & GSA & $\mathrm{T}(2 \mathrm{~m})$ & & & $\mathrm{v}$ & $\mathrm{v}$ \\
\hline 2 & CSIRO & GSA & $T(2 \mathrm{~m})$ & & & $\mathrm{v}$ & $\mathrm{v}$ \\
\hline 6 & ECHAM3/LSG 1,2 & GSA & $T(2 \mathrm{~m})$ & & $\mathrm{v}$ & $\mathrm{v}$ & $\mathrm{v}$ \\
\hline 2 & GFDL & GSA & $T(2 \mathrm{~m})$ & & & $\mathrm{v}$ & $\mathrm{v}$ \\
\hline 4 & HadCM3 & GSA & $T(2 \mathrm{~m})$ & $\mathrm{v}$ & $\mathrm{v}$ & $\mathrm{v}$ & $\mathrm{v}$ \\
\hline 8 & HadCM2 1-4 & GSA & $T(2 \mathrm{~m})$ & & & $\mathrm{v}$ & $\mathrm{v}$ \\
\hline 2 & NCAR-DOE & GSA & $T(2 \mathrm{~m})$ & & & $\mathrm{v}$ & $\mathrm{v}$ \\
\hline 2 & CCSR/NIES & GSA & $T(2 \mathrm{~m})$ & & & $\mathrm{v}$ & $\mathrm{V}$ \\
\hline
\end{tabular}


a

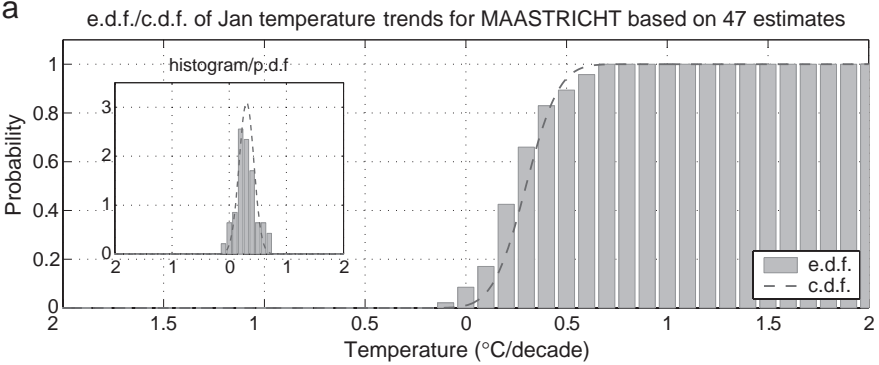

C

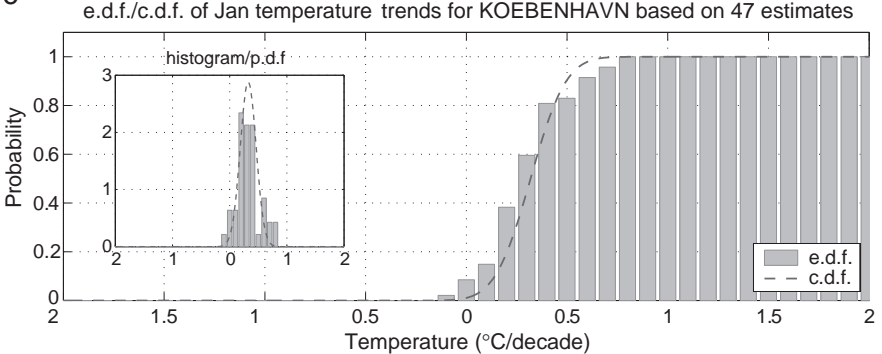

e

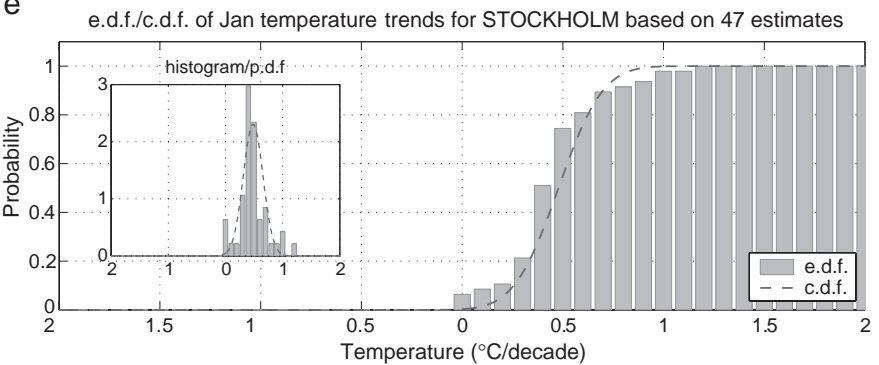

9 e.d.f./c.d.f. of Jan temperature trends for STYKKISHOLMUR based on 47 estimates

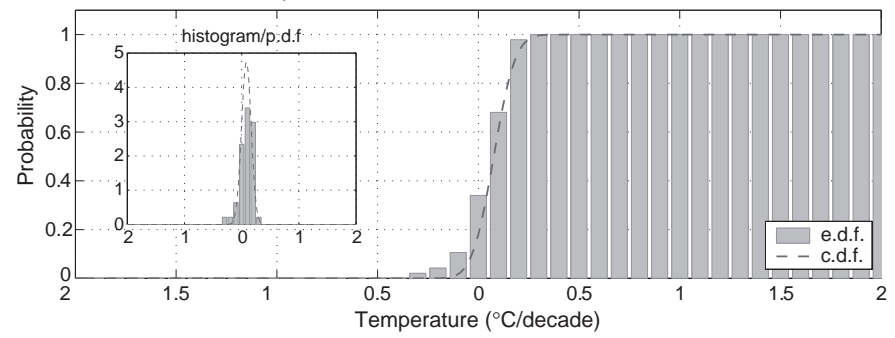

b

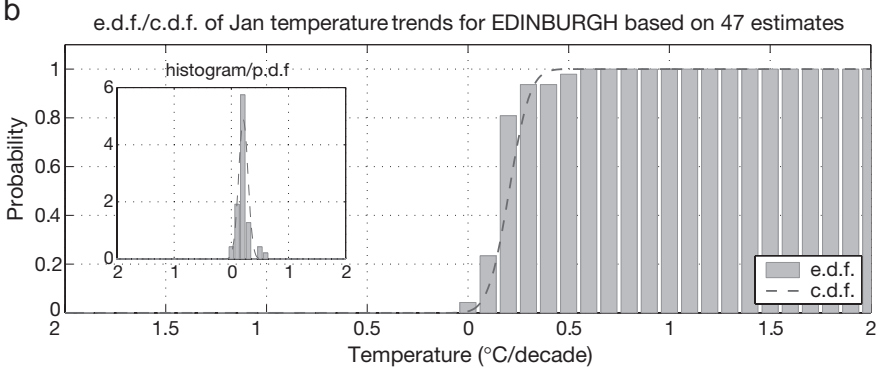

d
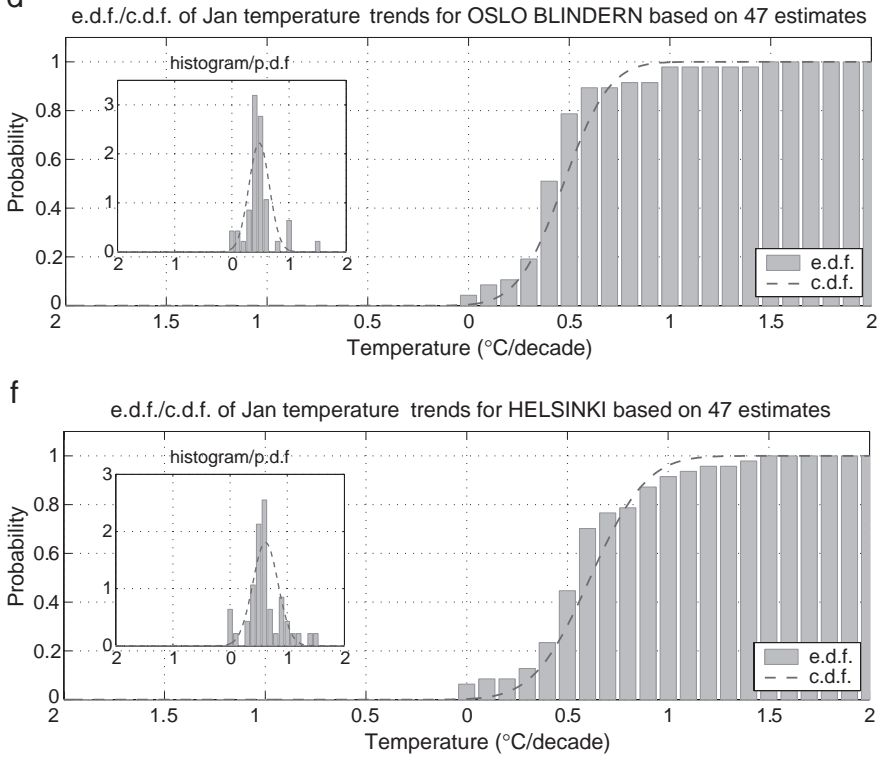

$\mathrm{h}$

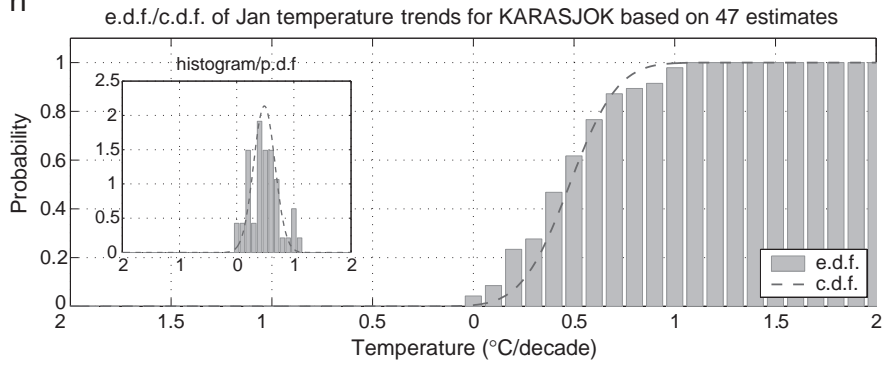

Fig. 6. Cumulative distribution of the various linear warming trend estimates. The diagrams are based on multi-model ensembles of empirical downscaled climate January temperature for (a) Maastricht, (b) Edinburgh, (c) Copenhagen, (d) Oslo, (e) Stockholm, (f) Helsinki, (g) Stykkisholmur, and (h) Karasjok

mation about which model is associated with the most realistic climate sensitivity. Columns 5 and 6 in Table 3 give the variance of the 2 leading modes for January and July respectively. The upper 4 rows list the corresponding variance derived using observations only, and provide a set of target measures for the combined fields of $T(2 \mathrm{~m})$. The leading mode derived from ECHAM4-GSDIO, HadCM3, HadCM2, CCCma, NCAR-DOE, NCAR-CSM, and GFDL results using the nordic domain accounts for less variance than the observations, which may be indicative of differences in the spatial structure described by the climate mod- els and seen in the observations. Conversely, for the smaller domain, the leading common EOF for ECHAM4-GSDIO, HadCM2 and CCSR/NIES is associated with higher variance than the leading EOF derived using observations only. This discrepancy may suggest that these models predict more energetic and simpler structures or that there is more small-scale structure in the observations (signal or noise). The GFDL model gives the smallest difference between the variance associated with the 2 leading modes derived using the nordic or scan domains. This may point to the GFDL model as giving the least realistic description of 
a

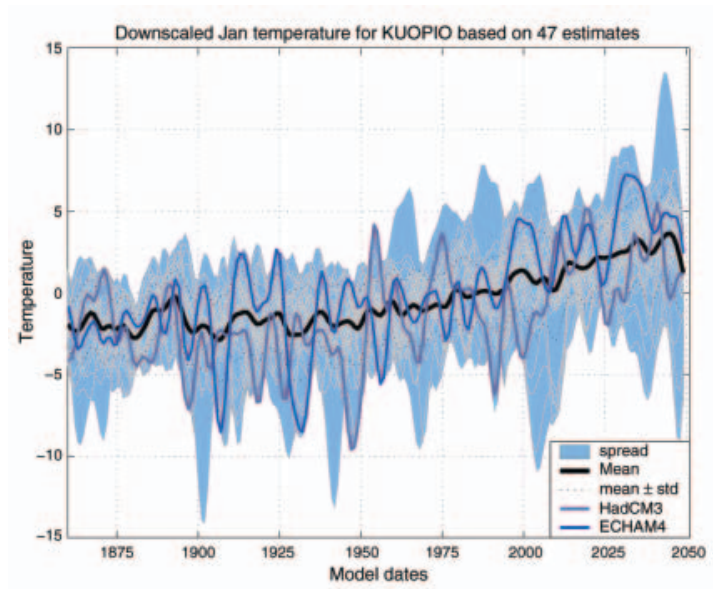

c

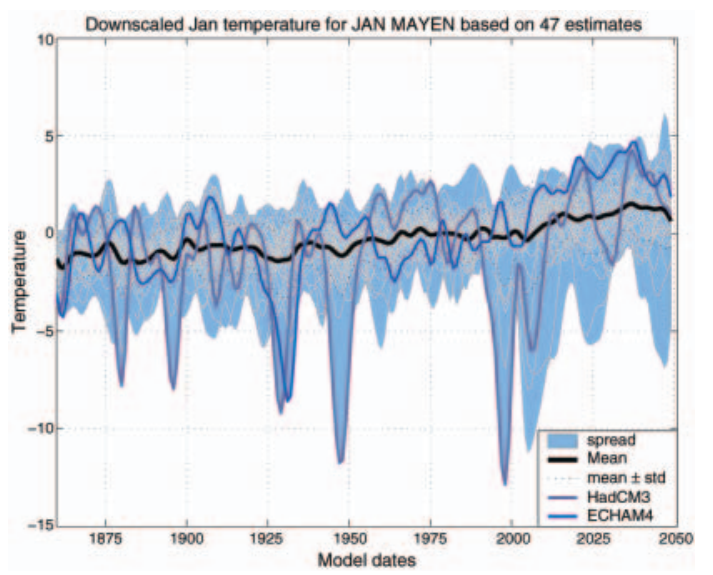

e
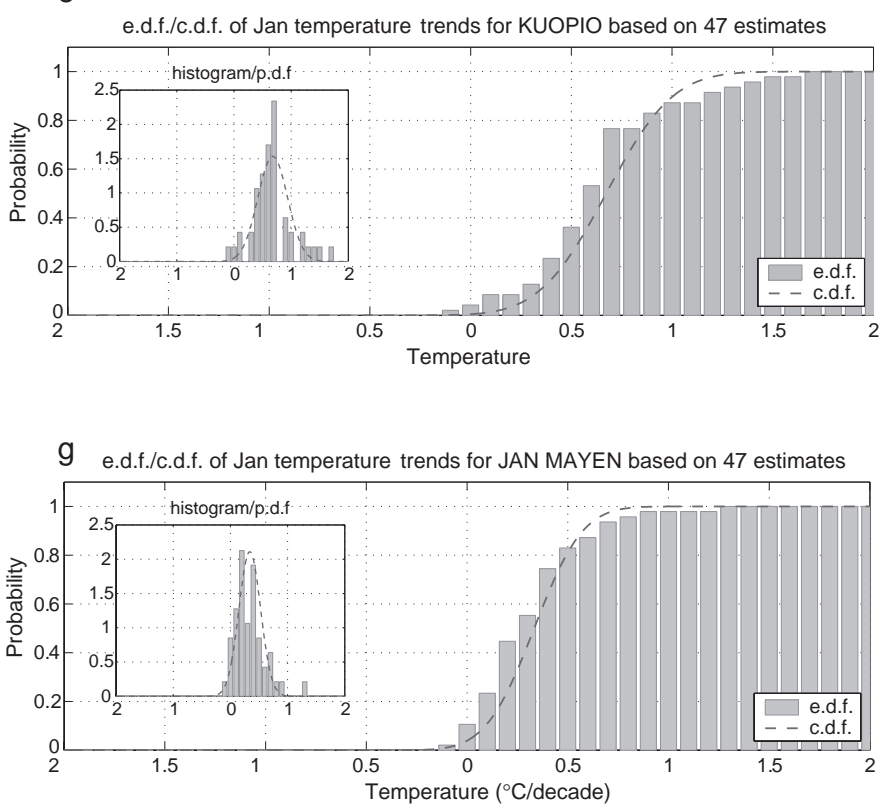

b

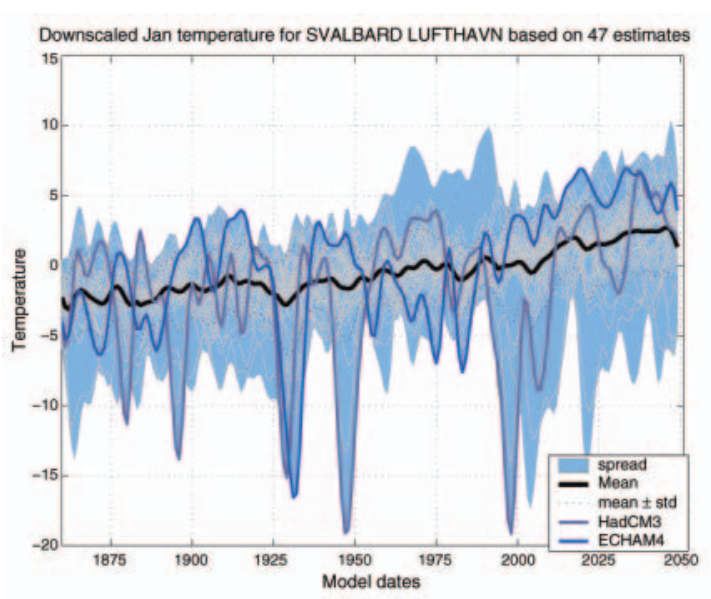

d

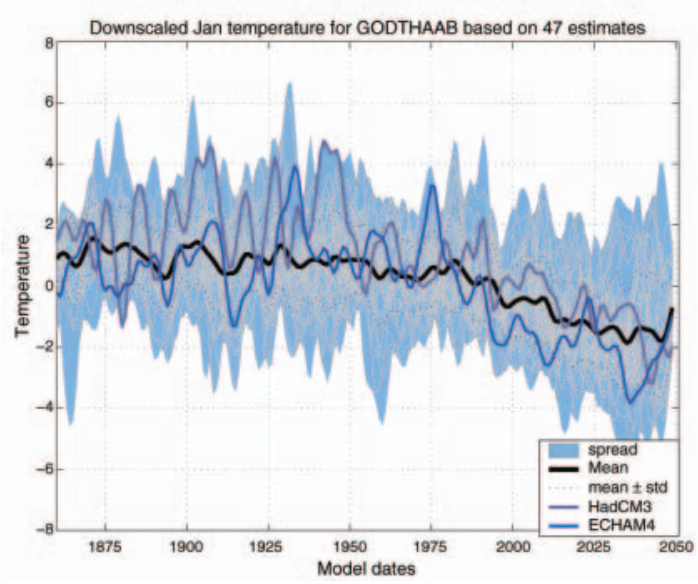

f

e.d.f./c.d.f. of Jan temperature trends for SVALBARD LUFTHAVN based on 47 estimates

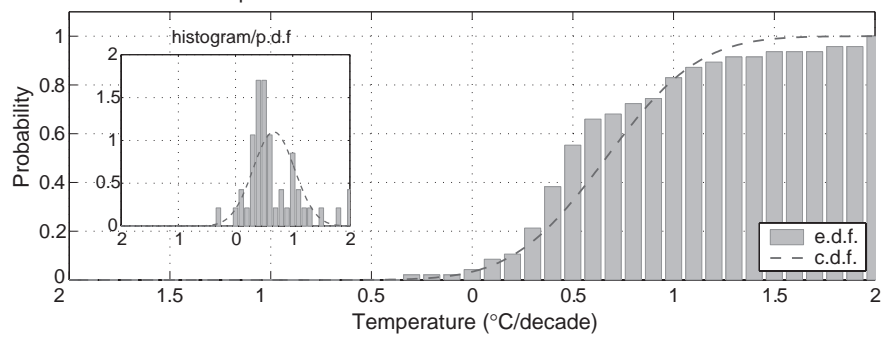

h

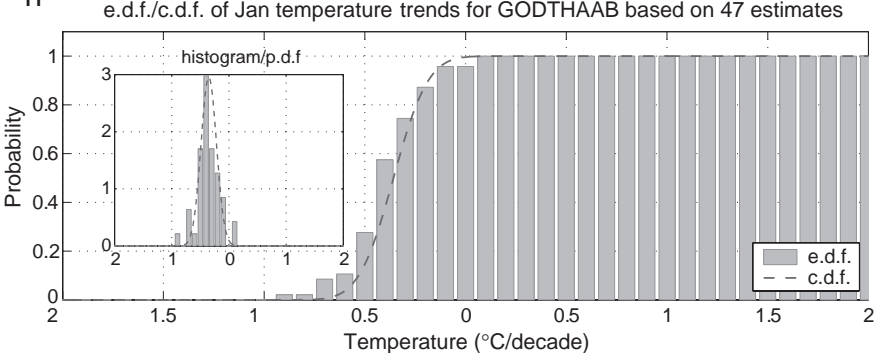

Fig. 7. Time-series plumes showing the multi-model ensemble mean and spread for empirically downscaled January temperature at 4 locations. (a-d) Plume plots for Kuopio (Finland), Svalbard, Jan Mayen, and Godthåb (Greenland); (e-h) the corresponding cumulative distributions. Note that Godthåb was outside the predictor domain of all but 3 of the calculations 
Table 3. Cross-validation scores of various empirical downscaling models for Oslo and the variance accounted for by the 2 leading EOFs

\begin{tabular}{|c|c|c|c|c|c|}
\hline Predictor domain & Scenario & $\mathrm{r}(\mathrm{Jan})$ & r(Jul) & $\begin{array}{c}\text { Jan } \\
\operatorname{Var}(E 1, E 2)\end{array}$ & $\begin{array}{c}\text { Jul } \\
\text { Var(E1, E2) }\end{array}$ \\
\hline natl & & & & 30,19 & 21,16 \\
\hline neurope & & & & 59,20 & 47,18 \\
\hline nordic & & & & 67,18 & 63,14 \\
\hline scan & & & & 58,28 & 61,21 \\
\hline natl $T(2 \mathrm{~m})$ & GSDIO & 0.85 & 0.70 & 27,22 & 28,10 \\
\hline neurope $T(2 \mathrm{~m})$ & GSDIO & 0.88 & 0.63 & 60,15 & 38,16 \\
\hline nordic $T(2 \mathrm{~m})$ & GSDIO & 0.88 & 0.67 & 53,18 & 37,16 \\
\hline $\operatorname{scan} T(2 \mathrm{~m})$ & GSDIO & 0.91 & 0.68 & 68,15 & 56,13 \\
\hline natl $T(850 \mathrm{hPa})$ & GSDIO & 0.87 & 0.60 & 27,21 & 35,10 \\
\hline neurope $T(850 \mathrm{hPa})$ & GSDIO & 0.87 & 0.73 & 60,17 & 46,16 \\
\hline $\operatorname{scan} T(850 \mathrm{hPa})$ & GSDIO & 0.92 & 0.74 & 80,10 & 67,17 \\
\hline neurope $H(500-700 \mathrm{hPa})$ & GSDIO & 0.84 & 0.80 & 47,27 & 56,16 \\
\hline nordic $H(500-700 \mathrm{hPa})$ & GSDIO & 0.71 & 0.75 & 52,23 & 57,16 \\
\hline $\operatorname{scan} H(500-700 \mathrm{hPa})$ & GSDIO & 0.80 & 0.78 & 75,12 & 73,13 \\
\hline natl $T(2 \mathrm{~m})$ & HadCM3 & 0.79 & 0.70 & 29,19 & 53,7 \\
\hline nordic $T(2 \mathrm{~m})$ & HadCM3 & 0.87 & 0.69 & 45,21 & 55,11 \\
\hline $\operatorname{scan} T(2 \mathrm{~m})$ & HadCM3 & 0.90 & 0.67 & 58,17 & 70,7 \\
\hline nordic $T(2 \mathrm{~m})$ & HadCM2 & 0.88 & 0.69 & 52,17 & 57,15 \\
\hline $\operatorname{scan} T(2 \mathrm{~m})$ & HadCM2 & 0.89 & 0.66 & 72,11 & 75,9 \\
\hline nordic $T(2 \mathrm{~m})$ & CCCma1 & 0.91 & 0.65 & 54,16 & 63,10 \\
\hline $\operatorname{scan} T(2 \mathrm{~m})$ & CCCma1 & 0.91 & 0.64 & 59,16 & 79,7 \\
\hline nordic $T(2 \mathrm{~m})$ & NCAR-DOE & 0.89 & 0.68 & 53,23 & 48,14 \\
\hline $\operatorname{scan} T(2 \mathrm{~m})$ & NCAR-DOE & 0.89 & 0.65 & 63,22 & 66,12 \\
\hline nordic $T(2 \mathrm{~m})$ & CCSR/NIES & 0.87 & 0.64 & 68,14 & 70,10 \\
\hline $\operatorname{scan} T(2 \mathrm{~m})$ & CCSR/NIES & 0.88 & 0.67 & 81,11 & 81,8 \\
\hline nordic $T(2 \mathrm{~m})$ & GFDL & 0.88 & 0.70 & 44,23 & 45,13 \\
\hline $\operatorname{scan} T(2 \mathrm{~m})$ & GFDL & 0.89 & 0.69 & 59,22 & 53,15 \\
\hline natl $T(2 \mathrm{~m})$ & NCAR-CSM & 0.85 & 0.66 & 31,21 & 36,10 \\
\hline neurope $T(2 \mathrm{~m})$ & NCAR-CSM & 0.90 & 0.60 & 55,19 & 47,15 \\
\hline nordic $T(2 \mathrm{~m})$ & NCAR-CSM & 0.84 & 0.66 & 49,23 & 44,16 \\
\hline $\operatorname{scan} T(2 \mathrm{~m})$ & NCAR-CSM & 0.91 & 0.61 & 61,22 & 68,10 \\
\hline
\end{tabular}

the surface temperature. ${ }^{1}$ For July, the ECHAM4GSDIO modes are different to the observations on the nordic domain scale, but the CCSR/NIES model describes modes on the scan domain scale with most variance or the least small-scale structure. The lack of systematic relationship between climate model and estimates of variance suggests that the uncertainty associated with the mode and variance estimation is large compared to inter-model differences. In summary, there is not a clear difference in the spatial modes described by the various climate models.

Previous work on model evaluation suggests that the climate models give a realistic description of the main features of the 'present-day' climate (Osborne et al. 1999, Benestad 2001a), but some models appear to give a slightly distorted reproduction of spring-time

\footnotetext{
${ }^{1}$ The GFDL temperature is taken from the $\sigma_{0.99}$ level rather than from the $2 \mathrm{~m}$ height
}

climate statistics (Osborne et al. 1999). Thus the findings of the present study are consistent with independent studies.

Table 4 shows warming trend scenarios downscaled for Oslo for winter and July. The minimum January estimate is $-0.03^{\circ} \mathrm{C}$ decade ${ }^{-1}$, the median $0.44^{\circ} \mathrm{C}$ decade $^{-1}$, the mean $0.48^{\circ} \mathrm{C}$ decade $^{-1}$, and the maximum $1.45^{\circ} \mathrm{C}$ decade $^{-1}$; the distribution has a tail towards the higher values. This tail is due to 2 outliers on the high side representing the NCAR-DOE and CCSR/NIES models. Of the 47 estimates, only 1 gives a negative estimate for January (HadCM2 member 3 using the scan domain) albeit indistinguishable from zero. Similar scenarios made with the same climate model but with different initial conditions give trends as high as $0.39^{\circ} \mathrm{C}$ decade ${ }^{-1}$ using the same downscaling options (the scan domain). One conclusion is therefore that the initial conditions matter for the climate scenarios. The large difference between 2 scenarios 
Table 4. Downscaled trend scenarios $\left({ }^{\circ} \mathrm{C}\right.$ decade $\left.{ }^{-1}\right)$ for January and July temperatures in Oslo derived from the 47 various climate models and using different downscaling options. ${ }^{*} \mathrm{p}<0.05,{ }^{* *} \mathrm{p}<0.01,{ }^{* * *} \mathrm{p}<0.001$

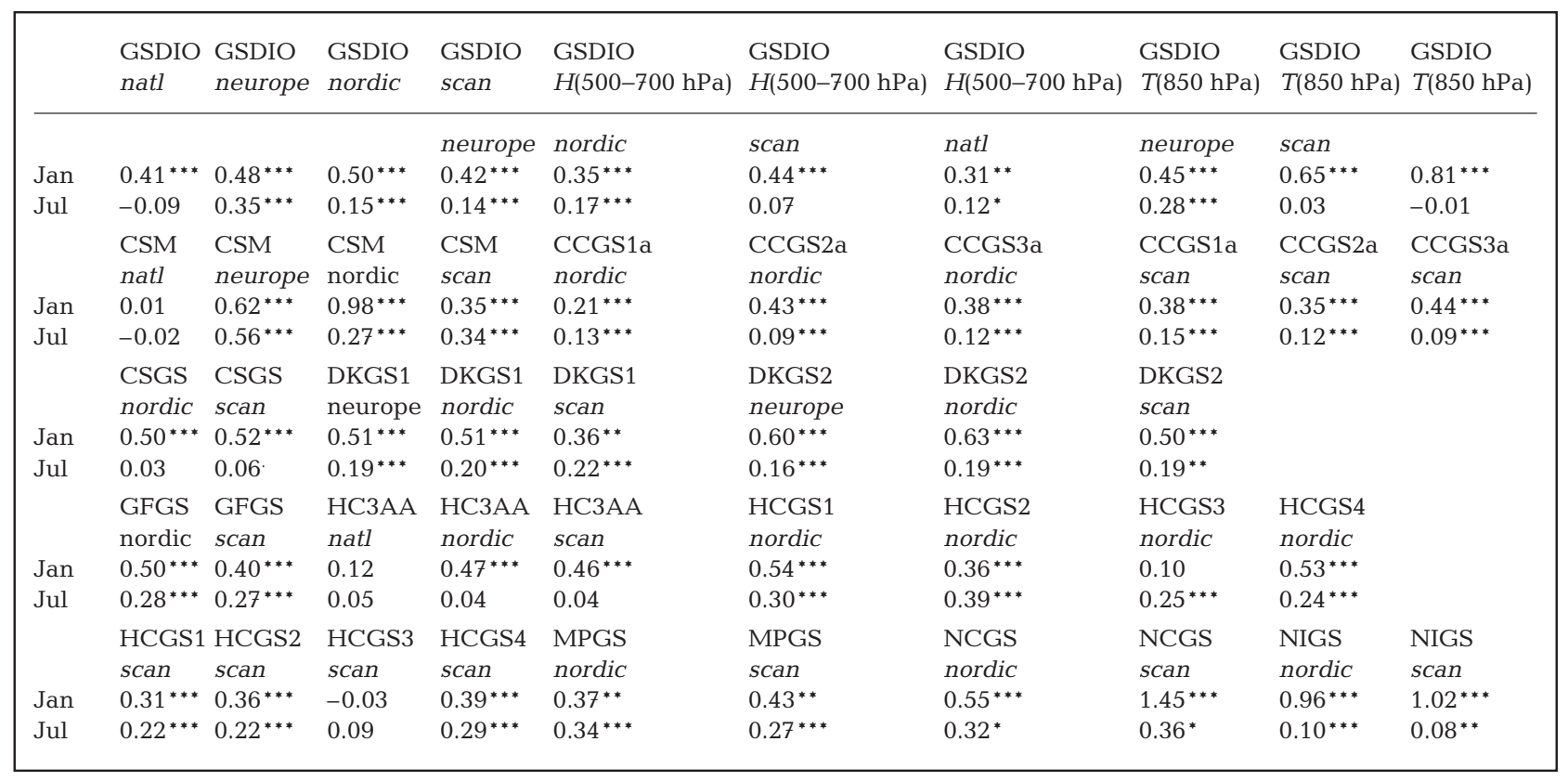

derived from the same climate model experiment, but with different downscaling-model choices (NCARCCSM with natl as the predictor domain gives $0.01^{\circ} \mathrm{C}$ decade $^{-1}$, whereas the nordic domain gives $0.98^{\circ} \mathrm{C}$ decade $^{-1}$ ), indicates that uncertainties in the empirical downscaling models can account for a substantial fraction of the spread in the trend estimates.

The July estimates are approximately normally distributed with a minimum of $-0.09^{\circ} \mathrm{C}$ decade $^{-1}$, a median of $0.17^{\circ} \mathrm{C}$ decade $^{-1}$, a mean of $0.18^{\circ} \mathrm{C} \mathrm{decade}^{-1}$, and a maximum of $0.56^{\circ} \mathrm{C}$ decade ${ }^{-1}$. The lowest estimate was obtained using the largest predictor domain natl and the ECHAM4-GSDIO experiment, but analysis with smaller domains $\left(0.35^{\circ} \mathrm{C}\right.$ decade $^{-1}$ using neurope) indicates that a substantial fraction of the range in the July estimates can be attributed to uncertainties in the relationship between large and small scales.

The downscaled multi-model ensemble mean for each location was interpolated onto a regular grid using kriging analysis (Gebhardt 2000) ${ }^{2}$ based on exponential, spherical, Gaussian, and linear-type variogram models (listed in Table 5). The model type was determined through trial and error. The details of the kriging are listed in Table 5 and the variogram models are shown in Fig. 8. These models (lines) give a reasonable description of the variogram values (points). The January, April and October maps were based on 48 scenarios: those 47 shown in Fig. 4 plus estimates using the combination of HadCM3 and neurope domain. ${ }^{3}$ The July results only included 46 estimates for each location, as 2 of the predictors (the scan domain, spanning $0^{\circ} \mathrm{W}-30^{\circ} \mathrm{E} / 55-75^{\circ} \mathrm{N}$, for 500 to $700 \mathrm{hPa}$ thickness and $T(850 \mathrm{hPa})$ predictors used with the ECHAM4-GSDIO scenario) did not produce skillful predictions for some of the locations.

Fig. 9 shows spatially interpolated maps, obtained through the kriging analysis, of multi-model ensemble mean warming rates for January, April, July and October. This analysis brings out a common signal in the various scenarios. In January (Fig. 9a), the enhanced warming is found over Finland and Svalbard $\left(\sim 0.6^{\circ} \mathrm{C}\right.$ decade $\left.{ }^{-1}\right)$, whereas in April (Fig. 9b) the warming is still strong over Svalbard $\left(\sim 0.3^{\circ} \mathrm{C}\right.$ decade $\left.^{-1}\right)$ but not in Finland $\left(0.2^{\circ} \mathrm{C}\right.$ decade $\left.{ }^{-1}\right)$. In July (Fig. 9c), the multi-model ensemble mean-warming-rate estimates suggest the strongest warming $\left(\sim 0.2^{\circ} \mathrm{C}\right.$ decade $\left.^{-1}\right)$ to occur over southern Finland, central Sweden, and midNorway. The strongest October warming $\left(\sim 0.3^{\circ} \mathrm{C}\right.$ de$\left.\mathrm{cade}^{-1}\right)$ is found in parts of southeastern Sweden and southwestern Finland (Fig. 9d).

The detailed information of the kriging analysis may not be representative if the uncertainty associated with the maps shown in Fig. 9 is high. There are several ways of investigating how much confidence one

\footnotetext{
${ }^{2}$ Gebhardt A (2000) The sgeostat package, v.1.0-10. A geostatistical package for R ('GNU S-plus'); available at http:// cran.r-project.org/

${ }^{3}$ This combination was accidentally left out in the earlier analysis. Derivation based on HadCM3 with the neurope domain gave moderate scenarios: Oslo trend estimate for January is $0.53^{\circ} \mathrm{C}$ decade $^{-1}$ and for July is $0.12^{\circ} \mathrm{C} \mathrm{decade}^{-1}$
} 

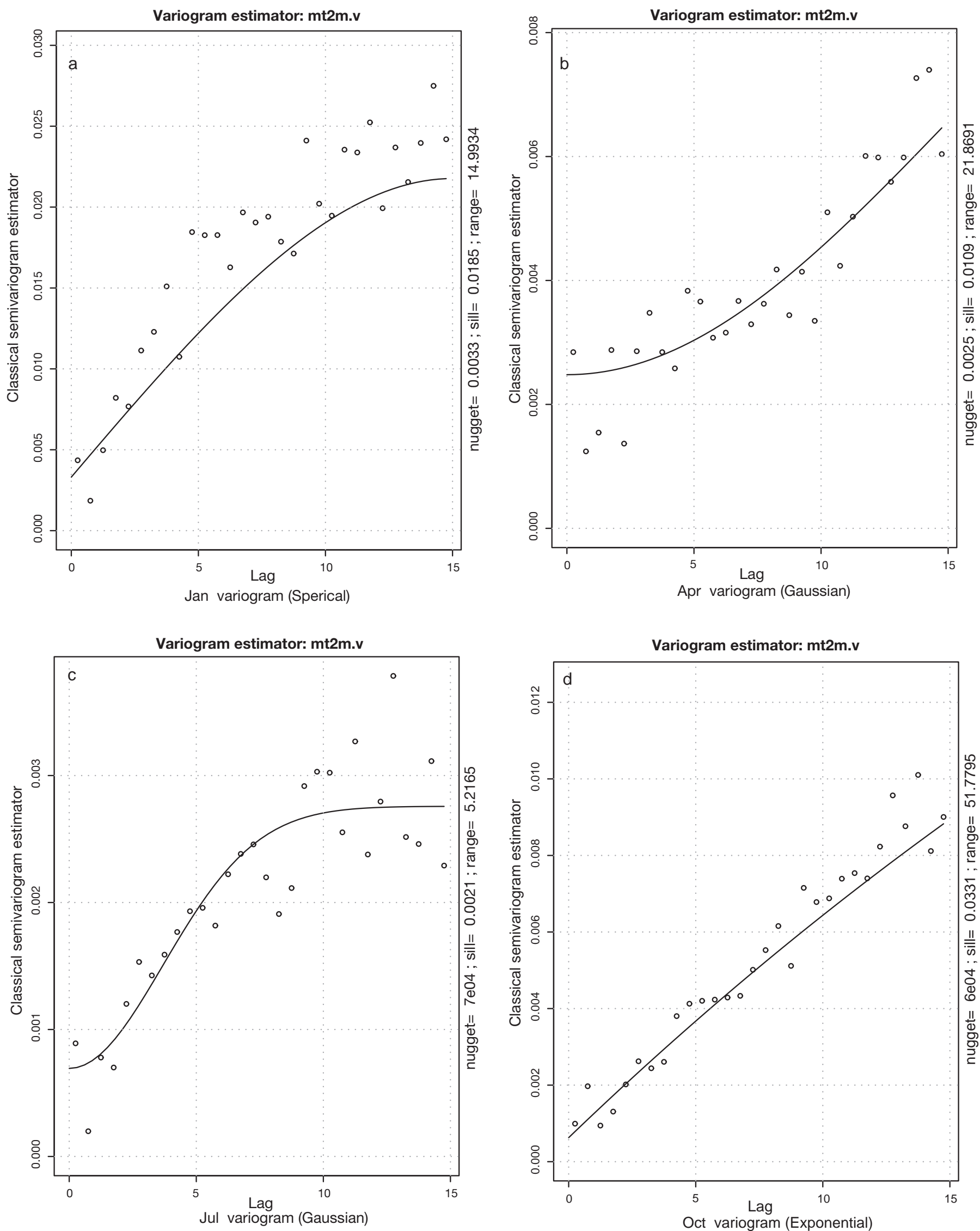

Fig. 8. Variograms for (a) January, (b) April, (c) July and (d) October 
Table 5. Details of the variogram models used in the kriging analysis. Nugget, sill and range: the 3 parameters describing the variograms (Fig. 8). The range is the separation between the points when an increase no longer causes a corresponding increase in the average square difference between pairs of values. The sill is the plateau the variogram reaches at the range. The nugget effect is the discontinuous vertical jump between 0 at zero distance (origin) and the variogram at extremely small distances of separation, for instance, caused by sampling errors. Note that the linear model does not use nugget, sill and range, but only nugget and slope

\begin{tabular}{|c|c|c|c|c|}
\hline Month & Nugget & Sill & Range & Model \\
\hline \multicolumn{5}{|c|}{ Ensemble mean } \\
\hline Jan & 0.003309 & 0.018457 & 14.993411 & Spherical \\
\hline Apr & 0.002479 & 0.010897 & 21.869121 & Gaussian \\
\hline Jul & 0.000693 & 0.002064 & 5.216452 & Gaussian \\
\hline Oct & 0.000628 & 0.033074 & 51.779508 & Exponential \\
\hline \multicolumn{5}{|c|}{ Ensemble spread } \\
\hline Jan & 0.000667 & 0.005777 & 14.99844 & Spherical \\
\hline Apr & 0.001086 & 0.014816 & 18.231722 & Gaussian \\
\hline Jul & 0.000185 & Slope & 0.000026 & Linear \\
\hline Oct & 0.000212 & 0.003247 & 16.64942 & Exponential \\
\hline
\end{tabular}

should place in these results. One way is to look at the multi-model ensemble spread (standard deviation), shown in Fig. 10. These maps were produced in a similar fashion to those in Fig. 9, but now the kriging analysis was applied to the multi-model ensemble standard deviation instead of mean value. The details of the variogram models used for these calculations are given in Table 5.

The results shown in Fig. 10a point to a high degree of scatter among the various projected January warming rate estimates for Svalbard $\left(\sim 0.4^{\circ} \mathrm{C}\right.$ decade $\left.^{-1}\right)$; however, the scatter is still smaller than the trends shown in Fig. 9. Thus, the signal-to-noise ratio is sufficiently high to pick out a common pattern among the various scenarios. But the models tend to produce more similar results for Finland $\left(\sim 0.3^{\circ} \mathrm{C}\right.$ decade $\left.^{-1}\right)$.

The comparison between the multi-model ensemble statistics for April (Fig. 10b) indicates that the mean trend is drowned in inter-model noise. Thus there is no clear model consensus for the spring.

The summer time trends are weak and the intermodel scatter is of a similar magnitude over most of Fennoscandia, making it difficult to identify any common traits if such exist. In the vicinity of the Bothnian Sea, however, the ensemble mean exceeds the ensemble spread.

In October, the highest values of the standard deviation $\left(\sim 0.2^{\circ} \mathrm{C}\right.$ decade $\left.{ }^{-1}\right)$ were found over parts of Norway/Sweden and southeastern Finland. For the October scenarios, on the other hand, there are some regions of enhanced warming that stand out above the noise level.
In order to assess how well the kriging interpolates the fields spatially, the estimated residual variance was plotted (Fig. 11). As expected, the regions with sparse data, such as the sea, are associated with a higher variance than regions over land, where there are observations.

\section{DISCUSSION}

Due to the spread among the different model warming-rate estimates, climate scenarios are associated with large uncertainties. There is nevertheless a general agreement on a future winter warming, despite the range of estimates, and there are some regions that seem to be exposed to stronger warming than others. For instance, most model scenarios suggest strongest wintertime warming for the continental climate types in the northeast (Finland) and weaker warming along the coasts. One would expect to find some regions with a stronger signal than noise due to the problem of multiplicity (Wilks 1995), but the significance of these can be estimated assuming a binomial probability distribution. There are 8 Finnish stations with a January trend exceeding $0.60^{\circ} \mathrm{C}$ decade ${ }^{-1}$, which exceeds the interscenario noise level by a factor of 2 . The probability that random trend estimates (centered around zero) should exceed the 'inter-model noise' level of around 2 standard deviations is about 0.02 , and the probability that this pattern is caused by 8 out of 48 independent random trends is vanishingly small ( $\mathrm{p}$-value $=7.6 \times 10^{-6}$ ) Due to spatial correlation between the stations, the trend estimates are not entirely independent, and the real probability is therefore higher than $7.6 \times 10^{-6}$. These results nevertheless seem highly significant, and these traits appear to be robust, regardless of the differences in the spatial resolution, the parameterisation schemes and the details of the downscaling analysis.

During spring, the predicted multi-model ensemble mean warming is weak and of the same magnitude as the spread in estimates. The mean January trend for all locations and all scenario-domain combinations is 0.36 , but it is only 0.16 for April. A Welch 2-sample $t$-test on all the January and April trend estimates gives a $t$-statistic of 38.28 and a p-value of less than $2.2 \times 10^{-16}$. Benestad (2000a) found that the ECHAM4 model describes the strongest warming in winter both for the 'past' and the 'future'. It is interesting to note that, while the clearest warming trend (most pronounced and significant) in observational Norwegian temperature records has been found during the spring season (Benestad 2001a), the springtime warming appears to be unrelated to changes in the circulation; Benestad (2001a) proposed that it is driven by changes in the radiation budget. But it is also possible that changes in the stratosphere, such as 
a

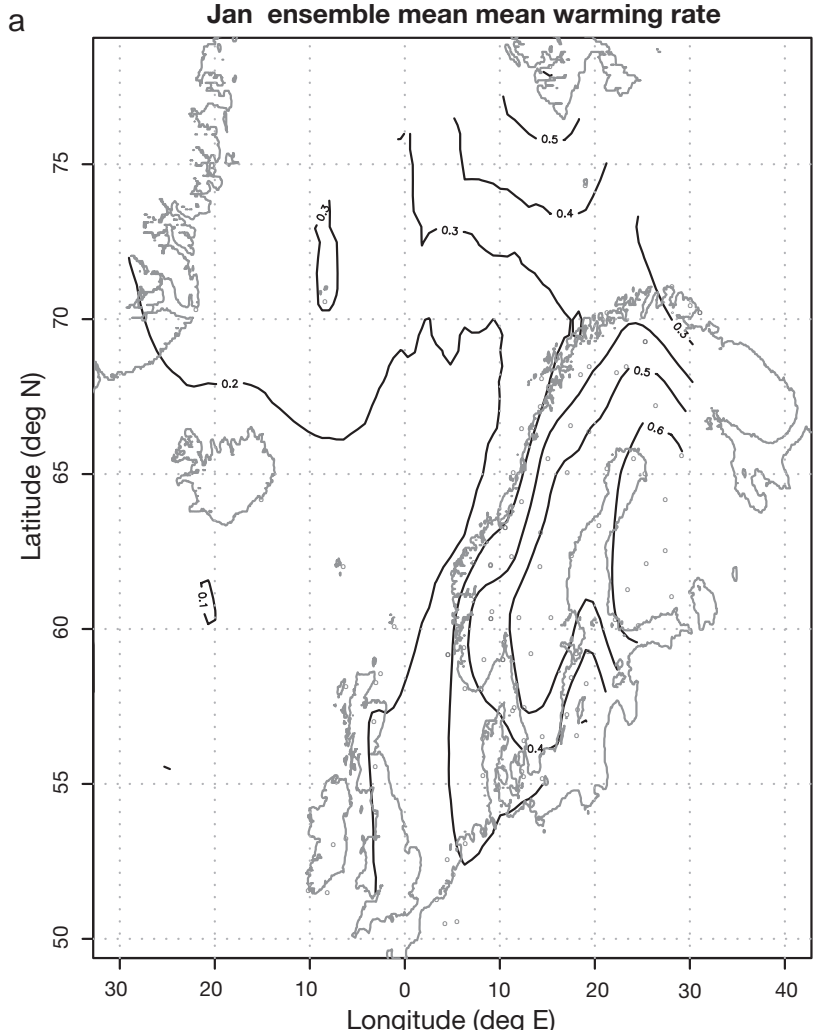

48 estimates for each of the 115 locations

C

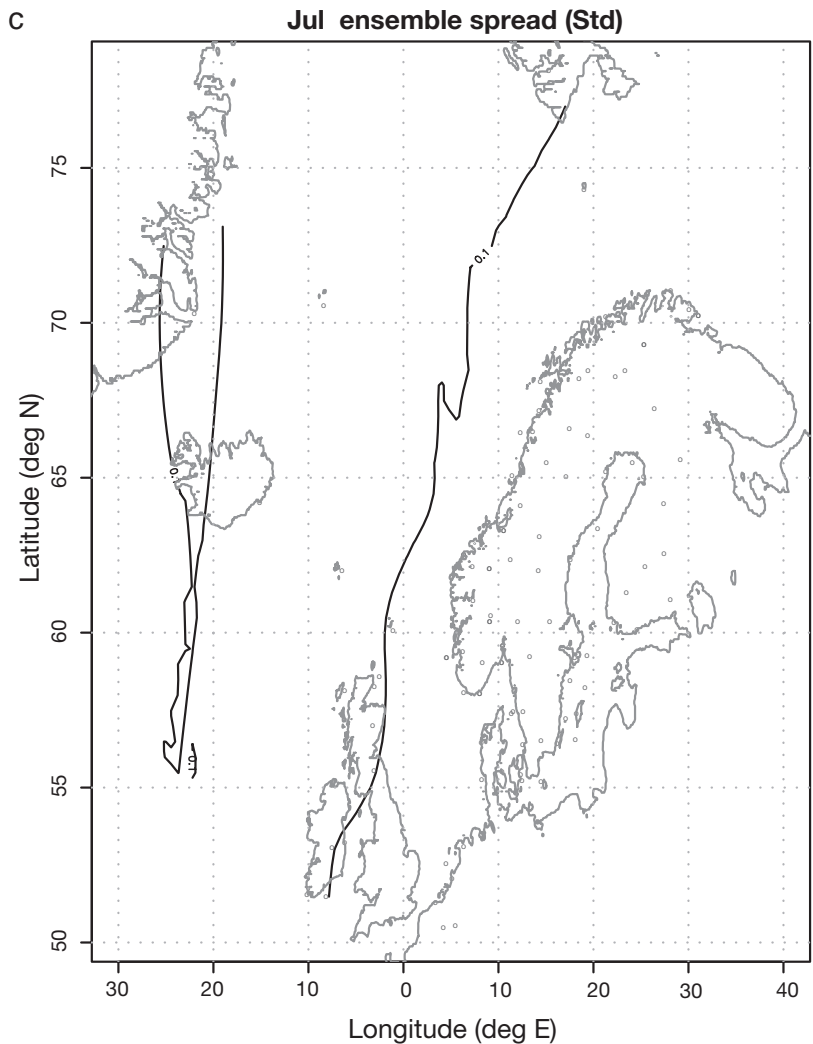

b

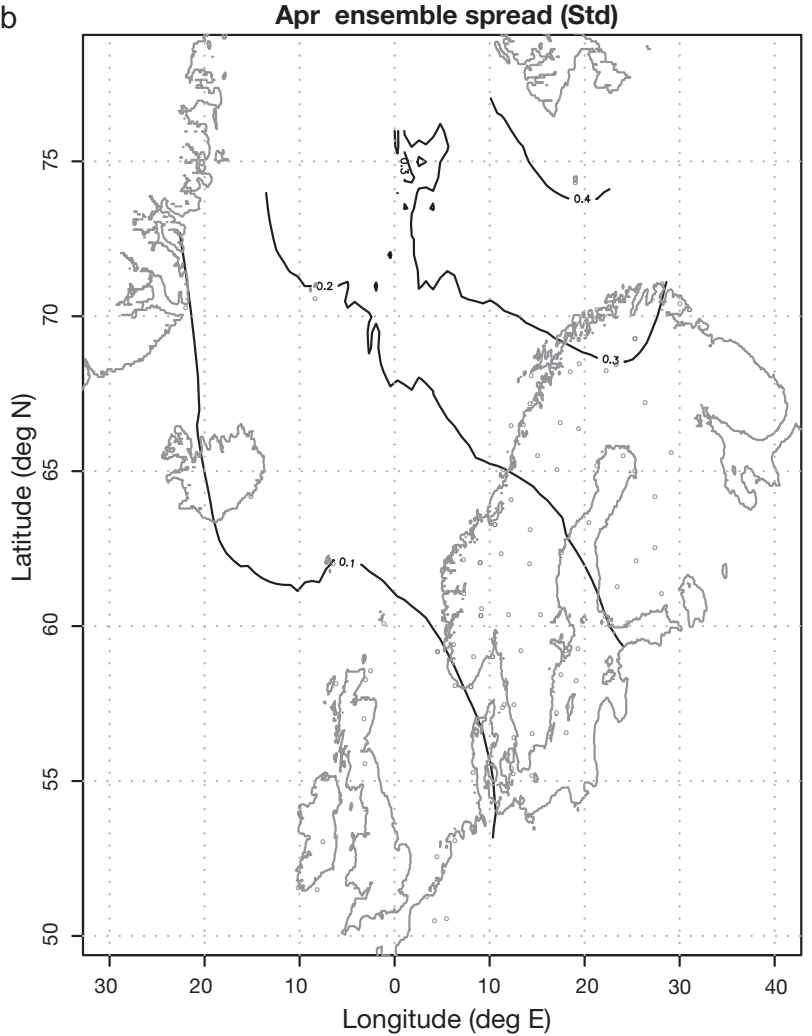

48 estimates for each of the 115 locations

d

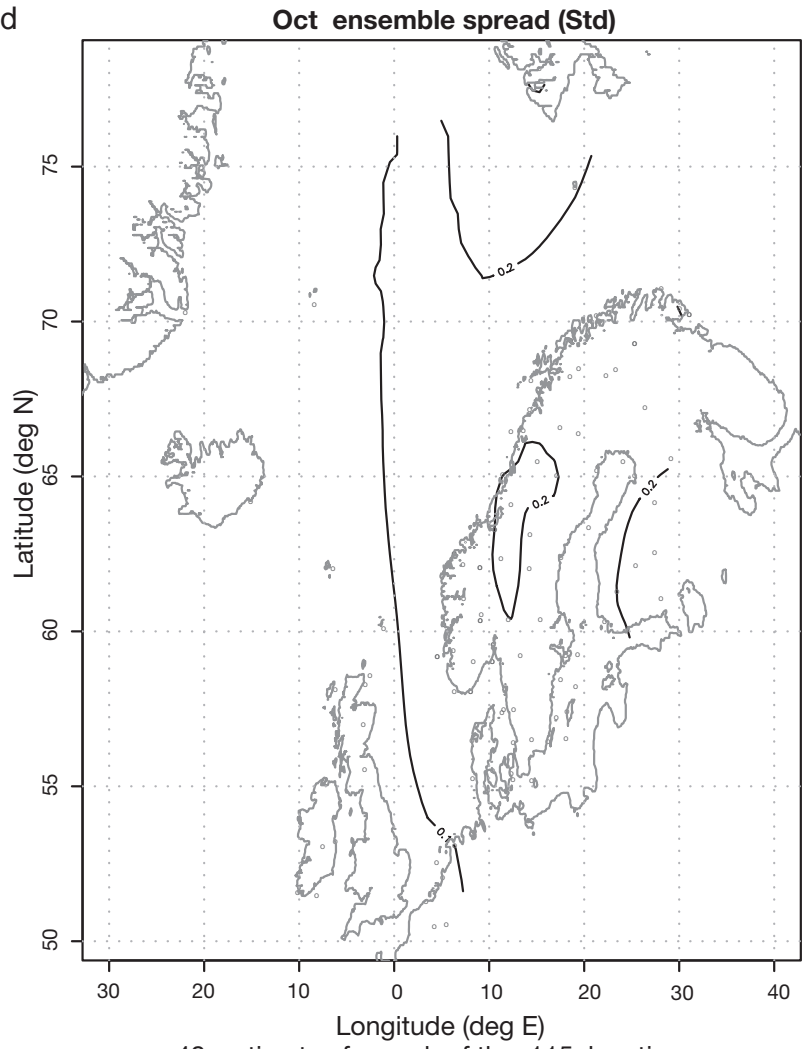

46 estimates for each of the 115 locations

48 estimates for each of the 115 locations

Fig. 9. Maps of multi-model ensemble mean warming rates for (a) January, (b) April, (c) July and (d) October, estimated by kriging. Maps are based on 48 estimates for each location, and include the 47 scenarios listed in Table 5 as well as the HadCM3 neurope combination (which had been accidentally excluded in the previous analysis), whereas the domains covering $0^{\circ} \mathrm{W}-30^{\circ} \mathrm{E}$, $55-75^{\circ} \mathrm{N}$ for $500-700 \mathrm{hPa}$ thickness and $T(850 \mathrm{hPa})$ predictors (ECHAM4-GSDIO) were excluded where the maps have been derived from only 46 estimates 


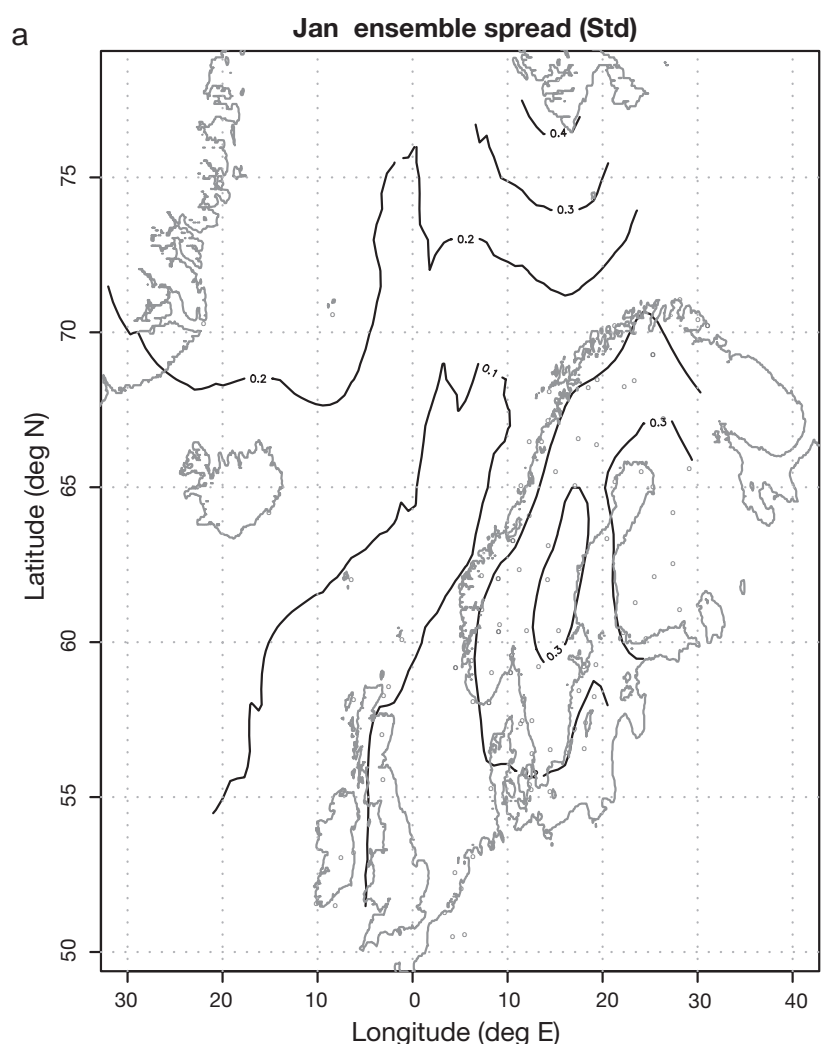

48 estimates for each of the 115 locations

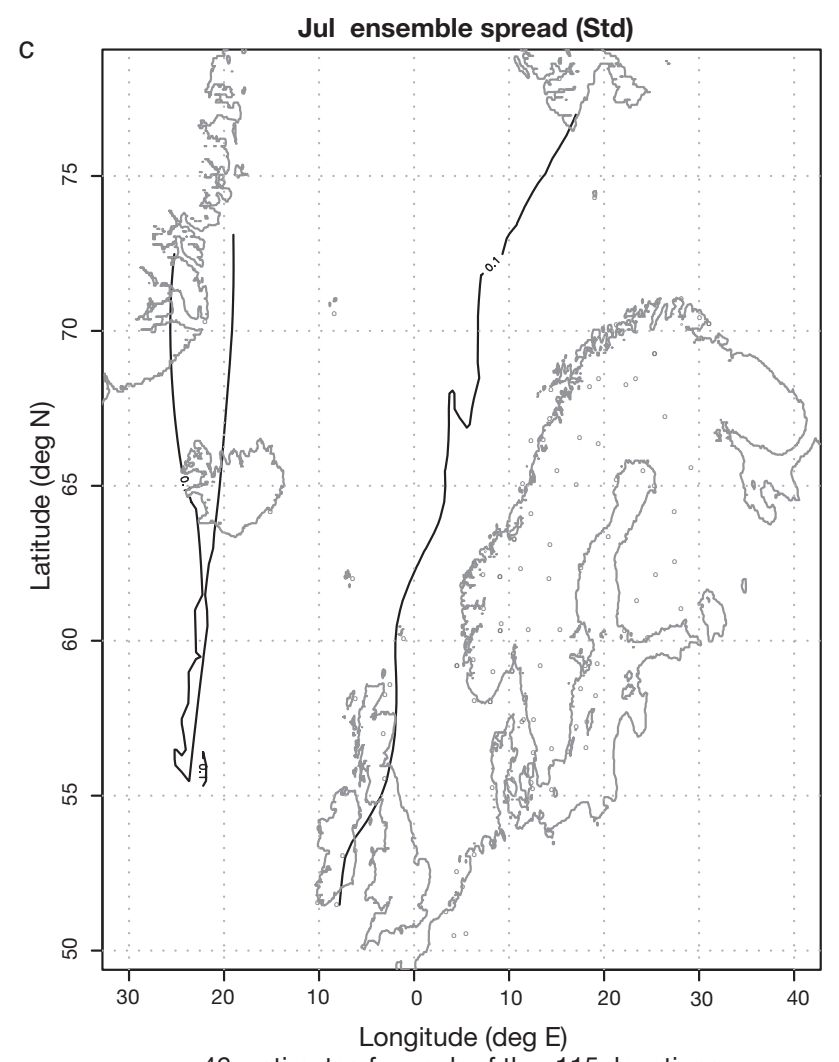

46 estimates for each of the 115 locations

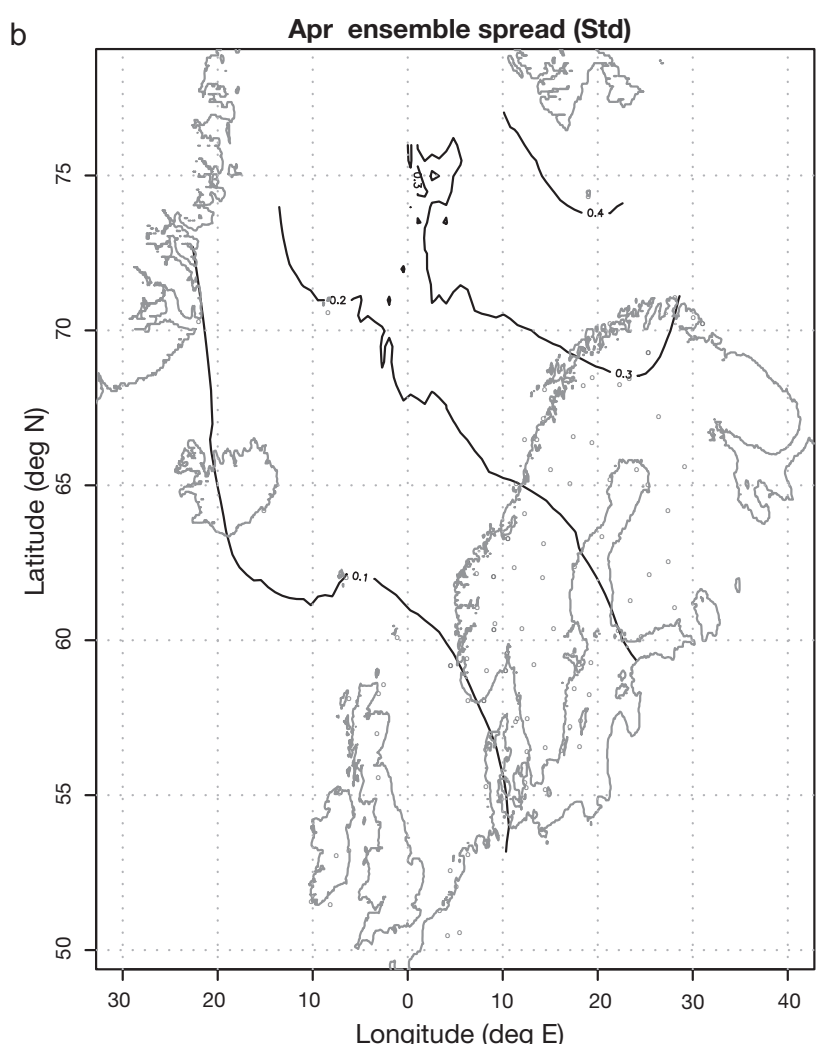

48 estimates for each of the 115 locations

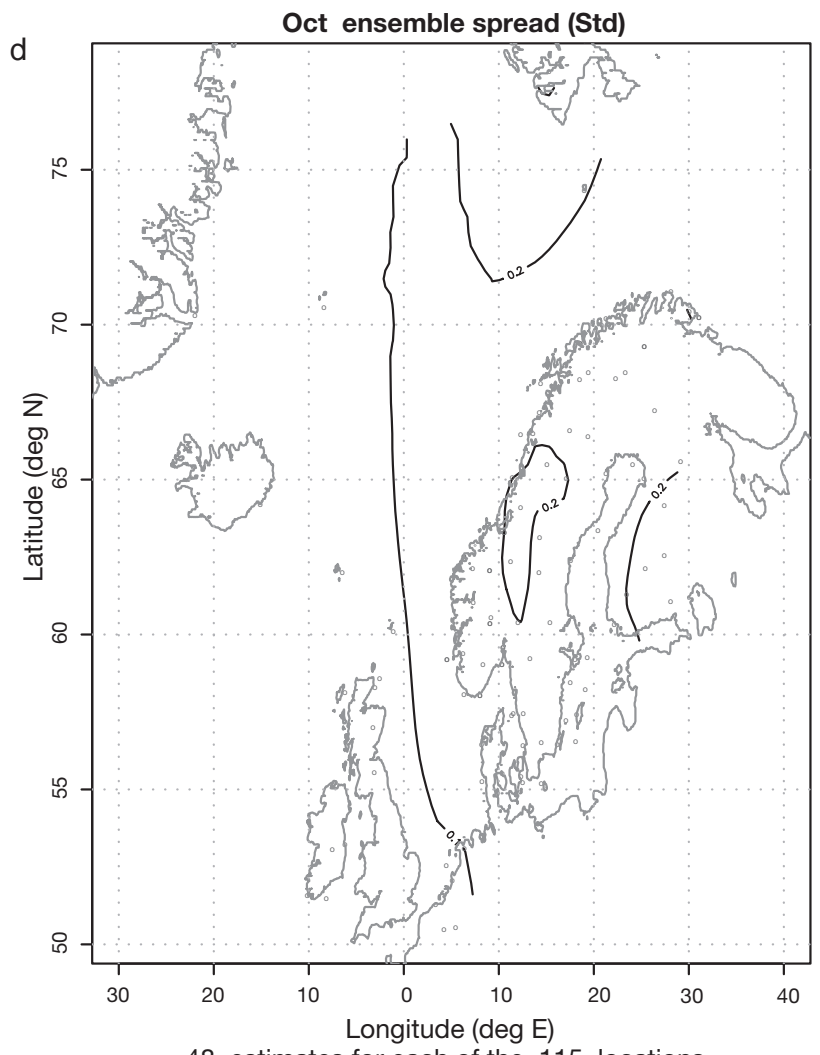

48 estimates for each of the 115 locations

Fig. 10. Maps of multi-model ensemble spread (SD) for (a) January, (b) April, (c) July and (d) October, estimated by kriging. Details as in Fig. 9 
a

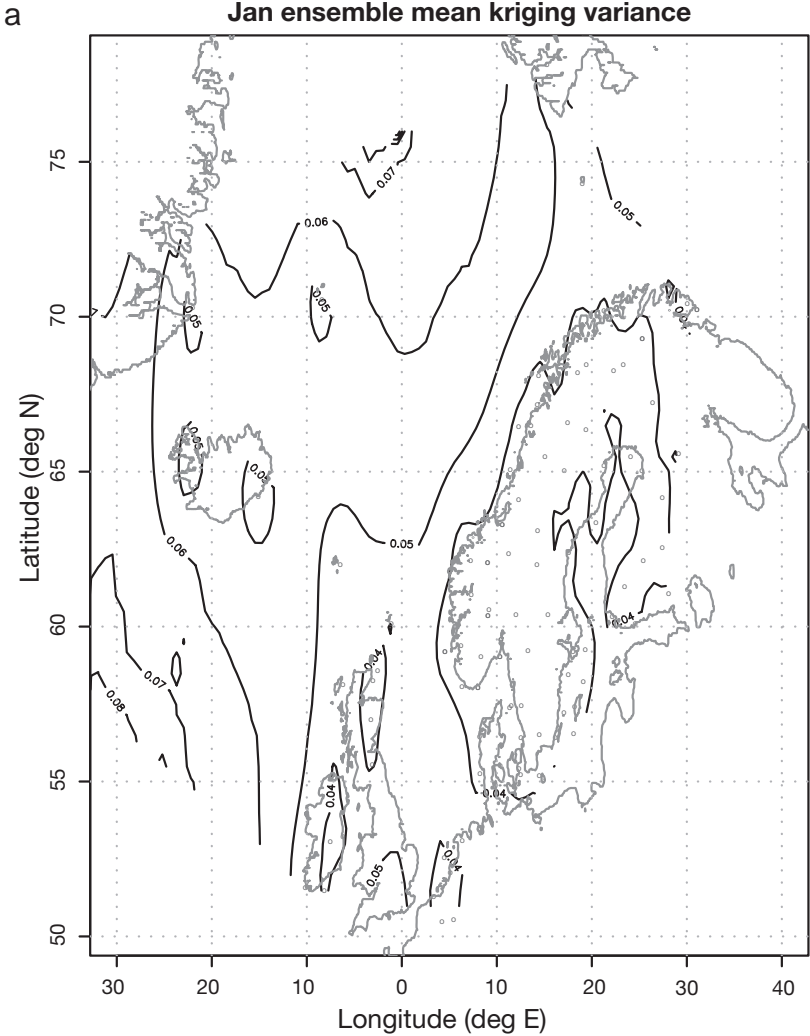

48 estimates for each of the 115 locations

C

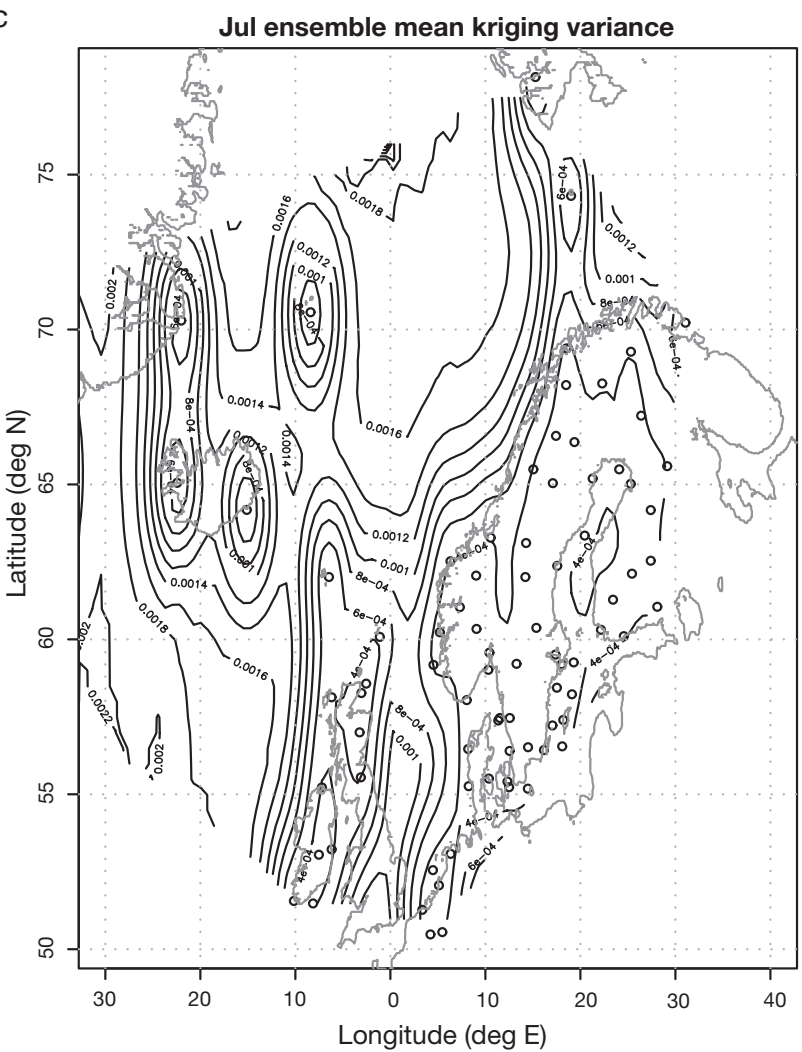

b

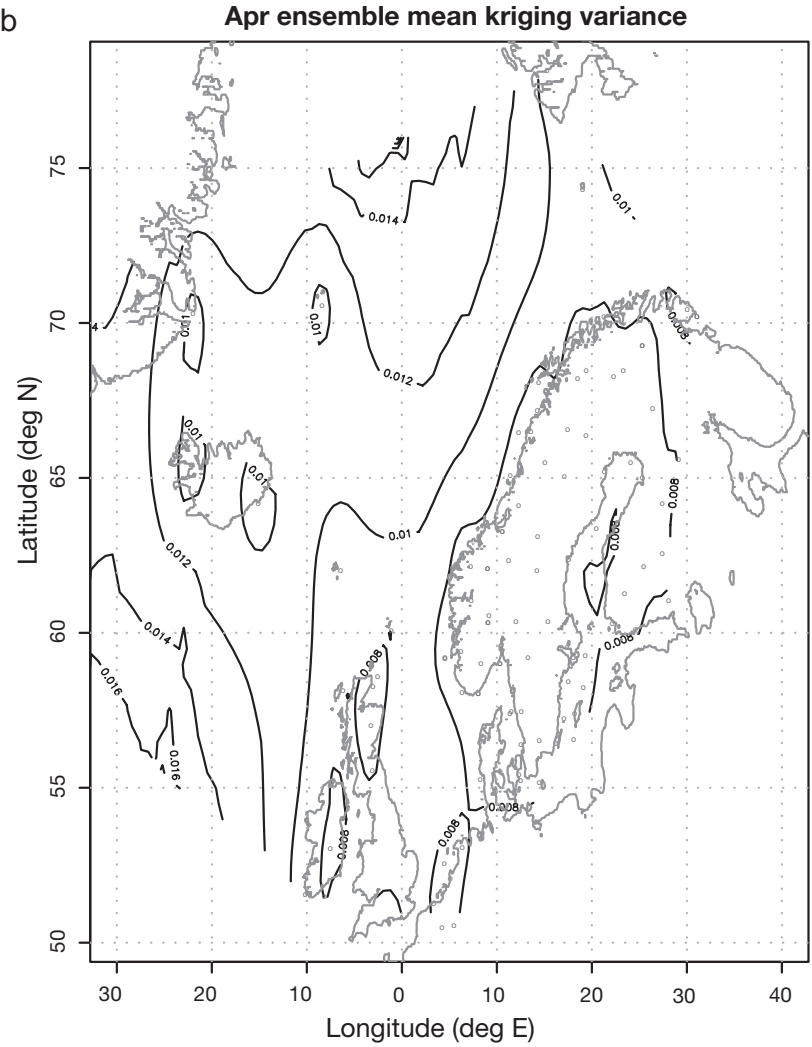

48 estimates for each of the 115 locations

d

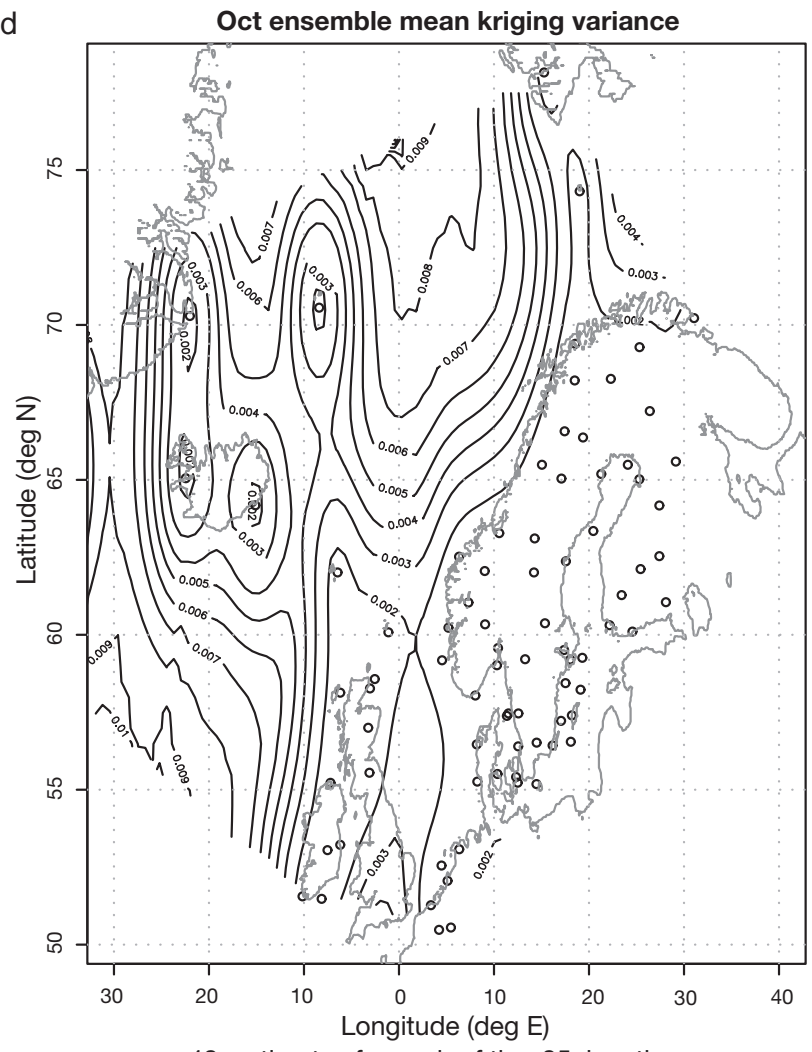

48 estimates for each of the 85 locations

Fig. 11. The variance field of the kriging analysis for (a) January, (b) April, (c) July and (d) October 
springtime ozone depletion, may play a role. Shindell et al. (2001) argued that the inclusion of the stratosphere is important for a realistic description of the long-term trends in the Arctic Oscillation (Thomson \& Wallace 1998). Thus, the difference in season when the strongest trend is observed may be a sign of a common systematic error in the climate models, possibly due to an exclusion of stratospheric processes.

The warming over the Bothnian Sea during July may be significant: a binomial probability distribution using 0.02 as a threshold (the probability exceeding twice the standard deviation) gives a p-value of $6.8 \times 10^{-7}$, but the real p-value is probably greater due to spatial correlation and smaller differences between the mean and standard deviation.

The high October warming rates over southeastern Sweden and southwestern Finland (inferred from estimates for 9 stations) stand out above the inter-model noise level, suggesting that this feature is a common feature in the various climate scenarios. However, the probability for normally distributed random numbers to exceed a noise level of around 1.5 standard deviations is about 0.07 , and the probability for more than 8 out of 48 is 0.02 . In other words, the autumn inter-scenario signal may be statistically significant at the $5 \%$ level.

It is assumed here that to a first approximation the inter-model spread can be interpreted as an uncertainty range, even though Allen et al. (2000) argue that doing so may be problematic because the models do not necessarily span the full range of known climate system behaviour. A spread in the various model estimates suggests that there is a high degree of uncertainty in the estimation of local climate scenarios. It is important to note that the converse is not necessarily true: a good agreement among the models does not mean that the future climatic evolution will follow these scenarios. The various models examined here have a range of different spatial resolutions and employ various parameterisation schemes. Some of these models are relatively old, whereas others are more recent and have a higher degree of sophistication. Furthermore, a number of these models employ flux correction methods in order to avoid artificial climate drifts, which may 'mask' serious model shortcomings as the flux correction sets a subjective constraint on the climate model. Hence, there may be reasons for categorizing the different models into 'poor' and 'good', and one could weight these accordingly in the analysis. Due to the high degree of complexity, such a task is difficult. Neither is such an approach desirable if one aims to explore the sensitivity of the downscaled scenarios to the choice of AOGCM and downscaling analysis details. The strategy adopted here already carries with it some degree of subjectivity, especially through the selection of ensemble of estimates; here the ECHAM4/OPYC3 GSDIO model scenario is overrepresented.

The approach proposed by Allen et al. (2000) involves scaling of the simulated trends using a spatiotemporal 'fingerprint' detection method. This approach aims at minimizing the uncertainty associated with internal climate variability. Such scaling, they observe, may also to some degree compensate for model shortcomings such as not accounting for all the important processes in the actual climate system. This means that the '1860-2050' trends in the AOGCM simulations are not so important for the final results for ' 2050 ', since the final trend information is derived through the 'fingerprint' analysis (analysis of inter-decadal variance) and the scaling of the AOGCM results. In other words, the fingerprint method used by Allen et al. (2000) addresses the issue regarding climate sensitivity. Here, a different tack was chosen, where the details in AOGCM results and the simulated trends were assumed to be important, but only those spatial patterns identified in the actual climate system as having a relationship with local climate variations were selected for further study. The results from the downscaling strategy adopted in this study are therefore more sensitive to the AOGCM simulations than in the method of Allen et al. (2000). The common EOF method employed here also contains an aspect of 'fingerprinting', albeit based on the spatial structure of natural variations instead of long-term trends. Barnett (1999) observed that anomalies under a global-warming scenario predicted by AOGCMs appear to have a similar structure to the natural spatial modes from the 'present-day' climate.

This paper presents some results from an ongoing downscaling analysis, and further work will be carried out to make local precipitation scenarios based on large-scale sea level pressure. Further sophistication of the common EOF downscaling analysis is also planned using 'mixed fields' for instance by combining SLP and $T(2 \mathrm{~m})$ fields prior to PCA. Analysis on daily mean variables from RegClim's dynamically downscaled results is also under preparation.

\section{CONCLUSION}

Empirically downscaled temperature scenarios are presented; they were derived utilising a new approach involving common EOFs. Using a multi-model ensemble in conjunction with empirical downscaling also constitutes a novel approach for deriving local climate scenarios.

The main findings in this study is that the warming is strongest in winter and at high latitudes both in the AOGCM results and the downscaled analysis. Strong warming is also projected for continental sites and the 
Barents Sea. This result is consistent with earlier results. There are also indications of stronger warming over the Bothnian Sea area during summer and autumn than for the rest of Fennoscandia. The strong warming signal over this region is a robust feature common for the different AOGCMs. The weak spring time trends in all of the climate models appear to be at odds with the observations, suggesting the clearest spring warming to be at locations in Norway. The downscaled trend estimates are slightly higher than the interpolated values from the AOGCMs. The various downscaled estimates have a small spread in the south, but a large scatter near the Arctic and in maritime regions, and sites near the North Sea give warming estimates with a small spread.

Evaluation of the climate model scenarios based on the common EOFs and regressional analysis does not suggest that there are clear superior and inferior mod- els in terms of describing the spatial structure of $T(2 \mathrm{~m})$ anomalies. There are, of course, substantial intermodel differences in the climate sensitivities, and 2 of models examined here give extreme estimates for the future climate trends. But the common EOF approach is not suitable for evaluating the climate sensitivity, and this aspect has not been addressed in this study.

Acknowledgements. I would like to thank my colleagues Eirik Førland, Inger Hansen-Bauer, and Ole Einar Tveito for valuable discussions and suggestions. The ECHAM4/OPYC3 GSDIO data were provided by Ole Vignes. This work was done under the Norwegian Regional Climate Development under Global Warming (RegClim) programme, and it was supported by the Norwegian Research Council (Contract NRC-No. 120656/720) and the Norwegian Meteorological Institute. Some of the plots in this paper were made with the GNU project's R data analysis tool (Gentleman \& Ihaka 2000, Ellner 2001; http://cran.r-project.org/).

Appendix 1. Method to combine gridded temperature anomalies with AOGCM results

Gridded temperature anomalies can be described mathematically in terms of an $M \times N$ matrix, $\mathbf{X}_{\text {obs, }}$ of which each of the $N$ columns holds the information on the spatial structure for the time of observation, $t$. A column representing the observations made at time $t$ can be written as a vector $\mathbf{x}_{t}=\left[x_{1}, x_{2}, \ldots, x_{M}\right]_{t}$, describing the spatial information at $M$ locations. If there are $N$ observations made over a time interval, then the mathematical expression for the data can be written as $\mathbf{X}=\left[\mathbf{x}_{1}, \mathbf{x}_{2}, \ldots, \mathbf{x}_{N}\right]$. Likewise, the gridded temperature anomalies from the climate model scenarios can be represented as $\mathbf{X}_{\mathrm{AOGCM}}$.

The climate model results were interpolated onto the same spatial grid as the observations. The gridded observations were detrended in order to avoid inflated correlation coefficients and related undesirable effects in the calibration of downscaling models (Benestad 2001a); however, the trends were not removed in the climate data as this would remove the climate-change signal. A composite data set was subsequently constructed by merging the detrended observations with the model data along the time axis, $\mathbf{X}=$ $\left[\mathbf{X}_{\text {obs, }}, \mathbf{X}_{\mathrm{AOGCM}}\right]$, by appending the rows of the climate model matrix to the rows of the observations.

The composite data was subject to singular-value decomposition (SVD), described by Strang (1995) and Press et al. (1989), in order to compute the right and left inverses of the data matrix:

$$
\mathbf{X}=\mathbf{U} \mathbf{\Lambda} \mathbf{V}^{T}
$$

The left inverse is a rectangular matrix (U) holding the right eigenvectors along its columns, each of which describing an 'eigenpattern' (also referred to as 'modes') and is equivalent to an ordinary PCA. The $M \times K$ matrix, where $M$ is the number of observational points (locations) and $K$ represents the total number of different modes, is equivalent to EOF analysis (Lorenz 1963, North et al. 1982, Wilks 1995, von Storch \& Zwiers 1999) when a geographical weighting is applied to the data so that the grid boxes representing smaller surface area carry proportionally less weight $\left(W_{i j}=\sqrt{\cos \Phi_{j}}\right.$, where $\cos \Phi_{j}$ is the latitude associated with the grid box). The eigenpatterns described by the columns in $\mathbf{U}$ hold no information about the time evolution of the data.

The right inverse (V) often is referred to as the 'principal components' in the geophysical literature, and this rectangular matrix describes the time evolution of the various eigenpatterns. The matrix $\mathbf{V}$ has the dimensions $N \times K$, where $N$ is the total number of contemporary observations made in time. The columns hold a set of weights used to determine the importance of each mode at each time when these are recombined to describe the spatial anomalies. The principal components can be divided into 2 subsections: $\mathbf{V}^{\mathrm{T}}=\left[\mathbf{V}_{\text {obs }}^{\mathrm{T}}, \mathbf{V}^{\mathrm{T}}\right.$ AOGCM $]$.

$\Lambda$ is a diagonal matrix holding the eigenvalues in descending order along its diagonal. It is common to discard the higher-order modes in order to simplify regression analysis and filter away noise. Here, only the leading 20 modes were kept $\left(\mathbf{U}_{M, K} \rightarrow \mathbf{U}_{M, 20}, \Lambda_{K, K} \rightarrow \Lambda_{20,20}, \mathbf{V}_{N, K} \rightarrow \mathbf{V}_{N, 20}\right)$.

A geographical weighting was used before the SVD, and an inverse scaling function was applied to the spatial patterns, $\mathbf{U}$, obtained from the SVD. The data were sub-sampled in accordance with North et al. (1982) to reduce any effects caused by autocorrelation. Sub-sampling the data also reduces effects introduced by discontinuities in between the observed and simulated data if the respective parts have non-zero autocorrelation. The time interval used for sub-sampling was determined according to which lag the serial correlation approached zero. The estimate for $\mathbf{V}$ was then computed by projecting the entire data set onto the eigenpatterns computed using the sub-sampled data: $\mathbf{V}^{\mathrm{T}}=\boldsymbol{\Lambda}^{-1} \mathbf{U}^{\mathrm{T}} \mathbf{X}$.

In the downscaling analysis, the part of the principal components corresponding to the DNMI temperature reconstruction $\left(\mathbf{V}_{\text {obs }}^{\mathrm{T}}\right)$ was used for model calibration based on CCA (Preisendorfer 1988, Wilks 1995, von Storch \& Zwiers 1999), and since the principal components are used, the analysis is similar to the method described in Barnett \& 
Appendix 1 (continued)

Preisendorfer (1987). The empirical models were seasonally stratified, with 1 model for each calendar month. A cross-validation (Wilks 1995, p. 194-198) analysis was employed to determine whether each pattern should be included or not. Those patterns which improved the crossvalidation Pearson correlation were selected for the model calibration. Only the $50 \mathrm{yr}$ period 1941-90 was used for model development, because one objective was to estimate warming rates for as many locations as possible and the different temperature records have different lengths. The CCA model, which consists of a linear transform (a matrix $\psi$ ) from the predictand $\mathbf{V}$ (principal components of gridded data) to the predictor $Y$ (station temperature records) can be described as follows:

$$
\hat{Y}=\psi \mathbf{V}_{\text {obs }}^{\mathrm{T}}
$$

where the matrix $\psi$ is the statistical model that can be used for prediction. The CCA between $\mathbf{V}_{\text {obs }}^{\mathrm{T}}$ and $Y$ yields canonical variates $(\mathcal{U}$ and $\mathcal{V})$, canonical correlation maps $(\mathcal{G}$ and $\mathcal{H})$, and a correlation matrix $(\mathcal{M})$, which form the basis for the statistical model. $Y$ can therefore be predicted from $\mathbf{V}_{\text {obs }}^{\mathrm{T}}$ according to:

$$
\hat{Y}=\mathcal{G M}\left(\mathcal{H}^{\mathrm{T}} \mathcal{H}\right)^{-1} \mathcal{H}^{\mathrm{T}} \mathrm{X}
$$

The CCA model is the matrix $\psi=\left[\mathcal{G} \mathcal{M}\left(\mathcal{H}^{\mathrm{T}} \mathcal{H}\right)^{-1} \mathcal{H}^{\mathrm{T}}\right]$. This model can be used with the principal components representing the AOGCM results, as these describe exactly the same spatial structures as $\mathbf{V}_{\text {obs. }}^{\mathrm{T}}$. Hence, downscaled scenarios can be derived according to:

$$
\hat{Y}_{\text {scenario }}=\psi \mathbf{V}_{\text {AOGCM }}^{\mathrm{T}}
$$

\section{LITERATURE CITED}

Allen MR, Stott PA, Mitchell JFB, Schnur R, Delworth TL (2000) Quantifying the uncertainty in forecasts of anthropogenic climate changes. Nature 407:617-620

Arrhenius (1896) On the influence of carbonic acid in the air upon the temperature of the ground. Phil Mag J Sci 41: 237-276

Barnett TP (1999) Comparison of near-surface air temperature variability in 11 coupled global climate models. J Clim 12: 511-518

Barnett TP, Preisendorfer RW (1987) Origins and levels of monthly and seasonal forecast skill for United States surface air temperatures determined by canonical correlation analysis. Mon Weather Rev 115:1825-1850

Benestad RE (2000a) Future climate scenarios for Norway based on linear empirical downscaling and inferred directly from AOGCM results. KLIMA 23/00. DNMI, Oslo

Benestad RE (2000b) Analysis of gridded sea level pressure and 2-meter temperature for 1873-1998 based on UEA and NCEP re-analysis II. KLIMA 03/00. DNMI, Oslo

Benestad RE (2001a) The cause of warming over Norway in the ECHAM4/OPYC3 GHG integration. Int J Climatol 21: 371-387

Benestad RE (2001b) A comparison between two empirical downscaling strategies. Int J Climatol 21:1645-1668

Bjørge D, Haugen JE, Nordeng TE (2000) Future climate in Norway. Research Report 103. DNMI, Oslo

Christensen OB, Christensen JH, Machenhauer B, Botzet M (1998) Very high-resolution climate simulations over Scandinavia - present climate. J Clim 11:3204-3229

Collins M (2000) Understanding uncertainties in the response of ENSO to greenhouse warming. Geophys Res Lett $27(21): 3509-3512$

Copley J (2000) The great ice mystery. Nature 408:634-636

Crane RG, Hewitson BC (1998) Doubled $\mathrm{CO}_{2}$ precipitation changes for the Susquehanna Basin: Downscaling from the Genesis General Circulation Model. Int J Climatol 18: 65-76

Cullen MJP (1993) The unified forecast/climate model. Meteorol Mag 122:81-94

Delworth TL, Broccoli AJ, Dixon K, Held I and 6 others (1999) Coupled climate modelling at GFDL: recent accomplishment and future plans. CLIVAR Exchanges 4:15-20
Ellner SP (2001) Review of R, Version 1.1.1. Bull Ecol Soc Am 82(2):127-128

Emori S, Nozawo T, Abe-Ouchi A, Numaguti A, Kimoto M, Nakajima T (1999) Coupled ocean-atmosphere model experiments of future climate change with an explicit representation of sulfate aerosol scattering. J Meteorol Soc Jpn 77(6):1299-1307

Flato GM, Boer GJ, Lee WG, McFarlane NA, Ramsden D, Reader MC, Weaver AJ (2000) The Canadian Centre for Climate Modelling and Analysis Global Coupled Model and its climate. Clim Dyn 16:451-467

Flury B (1988) Common principal components and related multivariate models. Wiley Series in Probability and Mathematical Statistics. Wiley, New York

Frich P, Alexandersson H, Ashcroft J, Dahlström and 13 others (1996) North Atlantic Climatological Dataset (NACD Version 1)-Final Report. Scientific report 1. DMI, Copenhagen

Gentleman R, Ihaka R (2000) Lexical scope and statistical computing. J Comput Graph Stat 9:491-508

Gordon C, Cooper C, Senior CA, Banks H and 4 others (2000) The simulation of SST, sea ice extents and ocean heat transports in a version of the Hadley Centre coupled model without flux adjustments. Clim Dyn 16:147-168

Gordon HB, O'Farrell SP (1997) Transient climate change in the CSIRO coupled model with dynamic sea ice. Mon Weather Rev 125:875-907

Grotch S, MacCracken M (1991) The use of general circulation models to predict regional climate change. J Clim 4: 286-303

Hartmann DL (1994) Global physical climatology. Academic Press, San Diego, CA

Heyen H, Zorita E, von Storch H (1996) Statistical downscaling of monthly mean North Atlantic air-pressure to sea level anomalies in the Baltic Sea. Tellus 48A:312-323

IPCC (2001) IPCC WGI third assessment report. Summary for policymakers. WMO, Geneva

Jones PD, Raper SCB, Bradley RS, Diaz HF and 2 others (1998) Northern Hemisphere surface air temperature variations, 1851-1984. J Clim Appl Meteorol 25:161-179

Kalnay E, Kanamitsu M, Kistler R, Collins W and 18 others (1996) The NCEP/NCAR 40-Year Reanalysis Project. Bull Am Meteorol Soc 77(3):437-471

Karl TR, Wang WC, Schlesinger ME, Knight RW (1990) A 
method of relating general circulation model simulated climate to the observed local climate. Part I: seasonal statistics. J Clim 3:1053-1079

Kidson JW, Thompson CS (1998) A comparison of statistical and model-based downscaling techniques for estimating local climate variations. J Clim 11:735-753

Lorenz E (1963) Deterministic nonperiodic flow. J Atmos Sci 20:130-141

Meehl GA, Collins WD, Boville BA, Kiehl JT and 5 others (2000) Response of the NCAR Climate System Model to increased $\mathrm{CO}_{2}$ and the role of physical processes. J Clim 13:1879-1898

Noguer M (1994) Using statistical techniques to deduce local climate distributions. An application for model validation. Meteorol Appl 1:277-287

North GR, Bell TL, Cahalan RF (1982) Sampling errors in the estimation of empirical orthogonal functions. Mon Weather Rev 110:699-706

Oberhuber JM (1993) Simulation of the Atlantic circulation with a coupled sea ice-mixed layer isopycnal general circulation model. Part 1: Model description. J Phys Oceanogr 22:808-829

Editorial responsibility: Hans von Storch, Geesthacht, Germany
Osborne TJ, Conway D, Hulme M, Gregory JM, Jones PD (1999) Air flow influences on local climate: observed and simulated mean relationships for the United Kingdom. Clim Res 13:173-191

Parkinson CL, Rind D, Healy RJ, Martinson DG (2001) The impact of sea ice concentration accuracy on climate model simulations with the GIS GCM. J Clim 14:2606-2623

Preisendorfer RW (1988) Principal component analysis in meteorology and oceanology. Elsevier Science, Amsterdam

Press WH, Flannery BP, Teukolsky SA, Vetterling WT (1989) Numerical recipes in Pascal. Cambridge University Press, Cambridge

Roeckner E, Arpe K, Bengtsson L, Dümenil L and 9 others (1992) Simulation of present-day climate with the ECHAM model: impact of model physics and resolution. Tech Rep 93, Max-Planck-Institut für Meteorologie, Hamburg

Roeckner E, Arpe K, Bengtsson L, Christof M and 6 others (1996) The atmospheric general circulation model ECHAM4: model description and simulation of presentday climate. Tech Rep 218. Max-Planck-Institut für Meteorologie, Hamburg

Submitted: March 25, 2001; Accepted: October 11, 2001 Proofs received from author(s): May 28, 2002 